\title{
Development of the Fischer-Tropsch Process: From the Reaction Concept to the Process Book
}

\author{
C. Boyer ${ }^{1 *}$, J. Gazarian' ', V. Lecocq ${ }^{2}$, S. Maury' ${ }^{2}$ A. Forret', J.M. Schweitzer' and V. Souchon ${ }^{3}$ \\ ${ }^{1}$ IFP Energies nouvelles, Process Design and Modeling Division, Rond-point de l'échangeur de Solaize, BP 3, 69360 Solaize - France \\ 2 IFP Energies nouvelles, Catalysis and Separation Division, Rond-point de l'échangeur de Solaize, BP 3, 69360 Solaize - France \\ ${ }^{3}$ IFP Energies nouvelles, Physics and Analysis Division, Rond-point de l'échangeur de Solaize, BP 3, 69360 Solaize - France \\ e-mail: christophe.boyer@ifpenergiesnouvelles.fr \\ * Corresponding author
}

\begin{abstract}
The process development by IFP Energies nouvelles (IFPEN)/ENI/Axens of a FischerTropsch process is described. This development is based on upstream process studies to choose the process scheme, reactor technology and operating conditions, and downstream to summarize all development work in a process guide. A large amount of work was devoted to the catalyst performances on one hand and the scale-up of the slurry bubble reactor with dedicated complementary tools on the other hand. Finally, an original approach was implemented to validate both the process and catalyst on an industrial scale by combining a 20 bpd unit in ENI's Sannazzaro refinery, with cold mock-ups equivalent to 20 and 1000 bpd at IFPEN and a special "Large Validation Tool" (LVT) which reproduces the combined effect of chemical reaction condition stress and mechanical stress equivalent to a 15000 bpd industrial unit. Dedicated analytical techniques and a dedicated model were developed to simulate the whole process (reactor and separation train), integrating a high level of complexity and phenomena coupling to scale-up the process in a robust reliable base on an industrial scale.
\end{abstract}

Résumé - Développement du procédé Fischer-Tropsch : du concept de réaction au dossier de procédé - Le développement par l'IFP Energies nouvelles (IFPEN), ENI et Axens d'un procédé Fischer-Tropsch est décrit. Ce développement est basé sur des études procédés en amont pour choisir le schéma de procédé, la technologie de réacteur, les conditions opératoires et en aval pour capitaliser tout le travail de développement dans un guide de procédé. Un effort particulier a été porté, d'une part, au développement de catalyseur, et d'autre part, à l'extrapolation du réacteur de type colonne à bulles slurry en utilisant une combinaison d'outils expérimentaux complémentaires. Une approche originale a été mise en place pour valider le procédé et le catalyseur à l'échelle industrielle, combinant un pilote de capacité de 20 bpd, basé dans la raffinerie ENI de Sannazzaro, des colonnes à bulles de 20 à 1000 bpd de capacité situées à l'IFPEN et un réacteur autoclave Large Validation Tool (LVT) qui permet de reproduire l'effet combiné des réactions chimiques et des cisaillements sur le catalyseur à l'échelle d'un réacteur de $15000 \mathrm{bpd}$. Des techniques analytiques dédiées ont été développées et un simulateur a été mis au point pour reproduire la section réactionnelle couplée à la section de séparation intégrant l'ensemble des phénomènes couplés pour garantir l'extrapolation du procédé de façon robuste et fiable. 


\section{NOTATIONS}

$a_{w} \quad$ Volumetric exchange area of the exchanger, $\mathrm{m}^{2} / \mathrm{m}^{3}$

$C_{i}^{*} \quad$ Adsorbed concentration of compound $i, \mathrm{~mol} / \mathrm{kg}$

$C_{i}^{l} \quad$ CO concentration in the liquid, $\mathrm{mol} / \mathrm{m}^{3}$

$C_{p_{\text {slurry }}} \quad$ Slurry heat capacity, $\mathrm{J} / \mathrm{kg} / \mathrm{K}$

$D \quad$ Column diameter, $\mathrm{m}$

$D_{a x} \quad$ Axial dispersion coefficient of the liquid, $\mathrm{m}^{2} / \mathrm{s}$

$d_{t} \quad$ Tube diameter, $\mathrm{m}$

$E_{j} \quad$ Activation energy, $\mathrm{J} / \mathrm{mol}$

$F_{i}^{g} \quad$ Molar flow rate of $i$ in the gas, mol/s

$F_{i}^{t o t} \quad$ Total flow rate of $i, \mathrm{~mol} / \mathrm{s}$

$G \quad$ Gravitation constant, $\mathrm{m} / \mathrm{s}^{-2}$

$H \quad$ Reactor height, $\mathrm{m}$

$H_{i} \quad$ Henry coefficient of $i, \mathrm{~Pa} . \mathrm{m}^{3} / \mathrm{mol}$

$k_{j} \quad j^{\text {th }}$ kinetic constant

$k_{L \cdot a} \quad$ Mass transfer coefficient, $\mathrm{s}^{-1}$

$n_{t} \quad$ Tube number

$P e_{M} \quad$ Liquid Peclet number

$P e_{T} \quad$ Thermal Peclet number

$P_{t} \quad$ Total pressure, bar

$r \quad$ Radial coordinate, $\mathrm{m}$

$\mathrm{R} \quad$ Constant of the ideal gas $8.314 \mathrm{~J} / \mathrm{mol} / \mathrm{K}$

$R \quad$ Column radius, $\mathrm{m}$

$r_{j} \quad$ Kinetic rate of reaction $\mathrm{j}, \mathrm{mol} / \mathrm{kg}$ cat $/ \mathrm{s}$

$S_{r} \quad$ Reactor section, $\mathrm{m}^{2}$

$T \quad$ Reactor temperature, $\mathrm{K}$

$T_{\text {cool }} \quad$ Cooling temperature, $\mathrm{K}$

$u \quad$ Axial liquid velocity, $\mathrm{m} / \mathrm{s}$

$U \quad$ Heat transfer coefficient, $\mathrm{W} / \mathrm{m}^{2} / \mathrm{K}$

$V_{L}(0) \quad$ Liquid centerline velocity, $\mathrm{m} / \mathrm{s}$

$v_{s g} \quad$ Superficial gas velocity, $\mathrm{m} / \mathrm{s}$

$v_{s l} \quad$ Superficial liquid velocity, $\mathrm{m} / \mathrm{s}$

$v_{s s} \quad$ Superficial solid velocity, $\mathrm{m} / \mathrm{s}$

$z \quad$ Vertical axis

\section{GREEK LETTERS}

$\alpha \quad$ Schultz-Flory parameter

$\beta$ Stoichiometric coefficient of the equivalent paraffin

$\Delta H_{j} \quad j^{\text {th }}$ reaction heat, $\mathrm{J} / \mathrm{mol}$

$\varepsilon_{g} \quad$ Gas holdup

$\varepsilon_{l} \quad$ Liquid holdup

$\varepsilon_{s} \quad$ Volumetric solid concentration in the slurry

$\varepsilon_{t} \quad$ Tube holdup

$\lambda_{a x} \quad$ Effective axial thermal conductivity, $\mathrm{W} / \mathrm{m} / \mathrm{K}$

$v_{t} \quad$ Turbulent viscosity

$\mu_{i j} \quad$ Stoichiometric of $i$ in reaction $j$

$\begin{array}{ll}\rho_{l} & \text { Wax density, } \mathrm{kg} / \mathrm{m}^{3} \\ \rho & \text { Liquid density, } \mathrm{kg} / \mathrm{m}^{3} \\ \rho_{s} & \text { Dry solid particle density, } \mathrm{kg} / \mathrm{m}^{3} \\ \rho_{\text {slurry }} & \text { Slurry density, } \mathrm{kg} / \mathrm{m}^{3} \\ \tau & \text { Liquid friction constraint } \\ \tau_{t} & \text { Tube friction constraint }\end{array}$

\section{INTRODUCTION}

IFP Energies nouvelles (IFPEN) has developed a FischerTropsch process in collaboration with ENI Technology and Axens whose purpose is to produce fuels from synthetic gas using Fischer-Tropsch synthesis. The market related to Low-Temperature Fischer-Tropsch (LTFT) processes has gained much interest in the last decade because they are able to match the increasing demand for Diesel and kerosene. These Fischer-Tropsch (FT) fuels have excellent combustion properties and low levels of sulfur, nitrogen aromatics and also particle matter precursors, which is a health advantage, especially for urban agglomerations and airports (Rahmim, 2009). Based on natural gas feed (Gas to Liquid, GtL) or coal feed (Coal to Liquid, CtL) for the production of synthetic gas, they contribute to diversifying and securing fuel sources. The ecological footprint can be clearly positive when using $\mathrm{CO}_{2}$ capture and storage or when developing FT based on biomass feed (Biomass to Liquid, BtL) (Viguié, 2007).

This paper describes the development strategy of the Fischer-Tropsch process ranging from the reaction concept and preliminary process studies to evaluate the best technology and provide the first process scheme up to the strategy to scale up the technology and catalyst before establishing the process guide for industrial proposal and unit design. The development of dedicated analytical techniques to properly quantify the feed and product composition, and dedicated software to predict unit performances and help unit operation is also presented. Although the GtL process can be economically very viable it is mandatory to demonstrate and scale it up to industrial size since these technologies are still relatively young and complex (Forbes, 2009). The process development strategy is thus a key point in order to identify and solve all technological issues and give confidence in the scale-up for future industrialization and commercialization.

\section{PRELIMINARY PROCESS STUDIES}

At the beginning of process development, it is required to estimate a first data set of operating conditions, define a process scheme and select the best adequate reactor technology 
and catalyst that will be optimized further during process development. These preliminary process studies are described in this section.

\subsection{Reaction Concept and Operating Conditions}

The FT reaction converts the syngas into linear paraffins.

$$
\underbrace{\mathrm{CO}+2 \mathrm{H}_{2}}_{\text {syngas }} \rightarrow \underbrace{-\left(\mathrm{CH}_{2}\right)-}_{n \text { paraffin }}+\mathrm{H}_{2} \mathrm{O} \quad \Delta H_{r}=-167 \mathrm{~kJ} / \mathrm{mol}
$$

The syngas is a mixture of carbon monoxide and hydrogen which can be obtained from partial oxidation followed by steam reforming or by autothermal reforming (combined reactions in a single reactor) when the feed is natural gas (methane).

The FT reaction follows a polymeric kinetic process which can be decomposed into 3 steps (simplified scheme):

- initiation step: formation of the first $\mathrm{CH}_{2}$ group;

- propagation step: chain length growth by addition of other $\mathrm{CH}_{2}$ groups;

- termination step: hydrogenation of the edge $\mathrm{CH}_{2}$ groups of a given chain.

The stoichiometry of the reaction also depends on the other product selectivities (mainly olefins and alcohols). According to the experimental data from the literature, the product selectivity for paraffins and olefins follows a Schulz-Flory distribution (Schultz et al., 1988). This Schultz-Flory distribution is based on the probability of chain length growth over the catalyst. The carbon number $n$ concentrations and the probability of chain growth, called the $\alpha$ value, are related to the molar ratio defined by:

$$
\alpha=\frac{C_{n+1}}{C_{n}} \quad(\text { molar ratio })
$$

This distribution is valid only for paraffins with at least two carbon atoms. For methane, it was shown in the literature that its selectivity is fixed by the catalyst and the operating conditions.

LTFT synthesis based on a cobalt support catalyst was selected by considering the high middle distillate yield (Fig. 1) and the growth demand of the market in Diesel and kerosene. The typical operating conditions of the LTFT are a temperature comprised between $200^{\circ} \mathrm{C}$ and $250^{\circ} \mathrm{C}$ with a syngas $\mathrm{H}_{2} / \mathrm{CO}$ ratio $\approx 2$, and a pressure between 20 and 35 barg.

\subsection{Choice of Reactor Technology and Catalyst Type}

For all catalytic reactor development, the choice and optimization of the reactor technology is based on the relationship

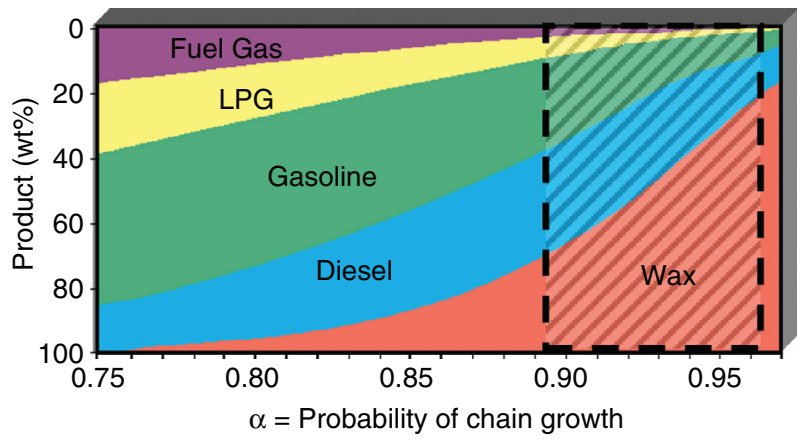

Figure 1

Fischer-Tropsch product distribution.

with the nature of the catalyst and the characteristics of the chemical reaction. For the Fischer-Tropsch Synthesis (FTS), the synergy between the catalyst and catalytic reactor is the key parameter since severe constraints are to be taken into account:

- heat extraction: FTS is a high exothermic reaction and isothermal conditions have to be maintained for product yield guarantee;

- separation of reaction products: gas, liquids (hydrocarbon and aqueous phases) and heavy hydrocarbon phase (waxes $\mathrm{C}_{20}-\mathrm{C}_{80}$ );

- catalyst management: the natural deactivation of the catalyst implies its replacement

The reactor technology for catalyst activation via a reduction step also has to be properly chosen and designed, but this reactor choice and scale-up will not be described in this paper.

A number of reactor technologies were investigated between 1925 and 1945 for FTS reaction and the most interesting were built on a laboratory or pilot scale. Two technologies were built industrially for the FTS with a low-temperature process and cobalt-based catalyst (Fig. 2, 3). Table 1 summarizes the main characteristics for the two technologies.

IFPEN investigated both solution and selected the slurry technology. The multitubular fixed reactor (ARGE type cf. Fig. 2) is composed of several thousands of tubes filled with extruded or ball catalysts $(2-3 \mathrm{~mm}$ diameter). The typical diameter of one tube is a few centimeters with a length of $10 \mathrm{~m}$. The gas reactant is injected at the top of the reactor (downflow circulation) and liquid product is recovered at the bottom of the shell. The heat extraction is easily operated by water under pressure around the tube (shell side) with vapor production. Despite the good thermal heat exchange, it is not possible to be in isothermal conditions and 


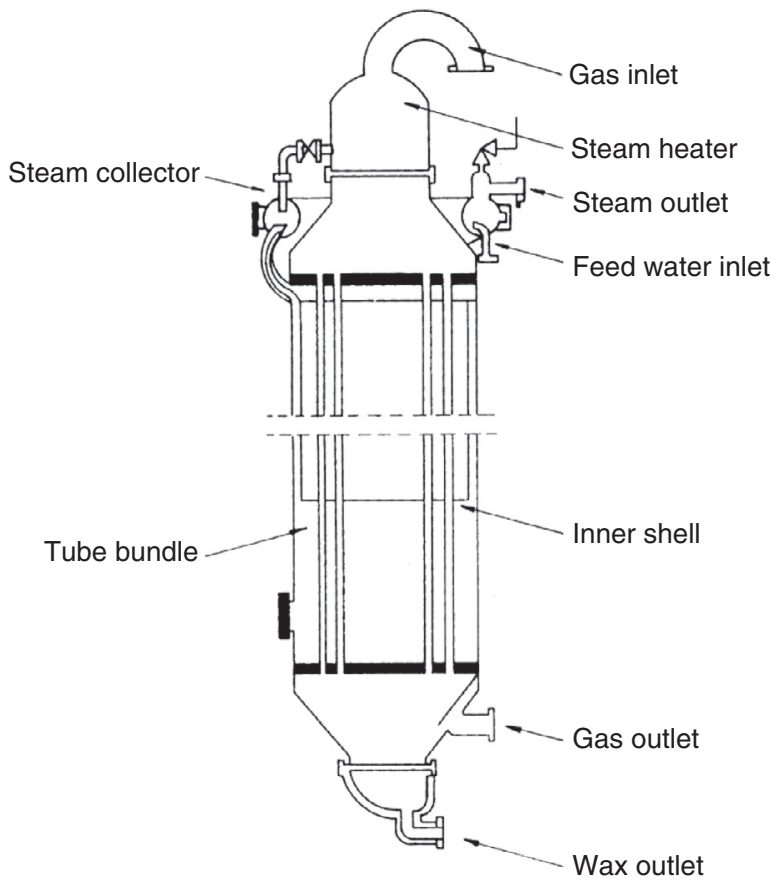

Figure 2

MultiTubular Fixed Bed Reactor (MTFBR) (from Dry, 2002).

the capacity per train is limited. Scale-up of such technology implies a very high number of parallel tubes, requiring a long time period to replace catalysts after deactivation.

The slurry bubble column reactor is based on the use of catalyst powder (mean grain diameter of $50 \mu \mathrm{m}$ ). The reactor is composed of a vertical vessel where the three phases are in contact (Fig. 3): the gas reactant injected at the bottom of the reactor and liquid product where the catalyst is in suspension. An internal heat-exchanger tube (bundle type) with medium pressure steam generation allows the heat extraction. The gas products are evacuated at the top of the column and the liquid/solid phase is laterally withdrawn. The slurry bubble column hydrodynamics has many advantages for the FTS application:

- a high liquid mixing, which provides homogeneous catalyst concentration and temperature: thus, an efficient heat transfer and temperature are obtained;

- the use of catalyst powder size avoids intra-granular diffusional limitations;

- easy catalyst addition and withdrawal.

The main difficulty of this technology is the scale-up and design criteria, and in-depth $R \& D$ effort required to obtain reliable process design rules from the pilot scale to industrial scale.

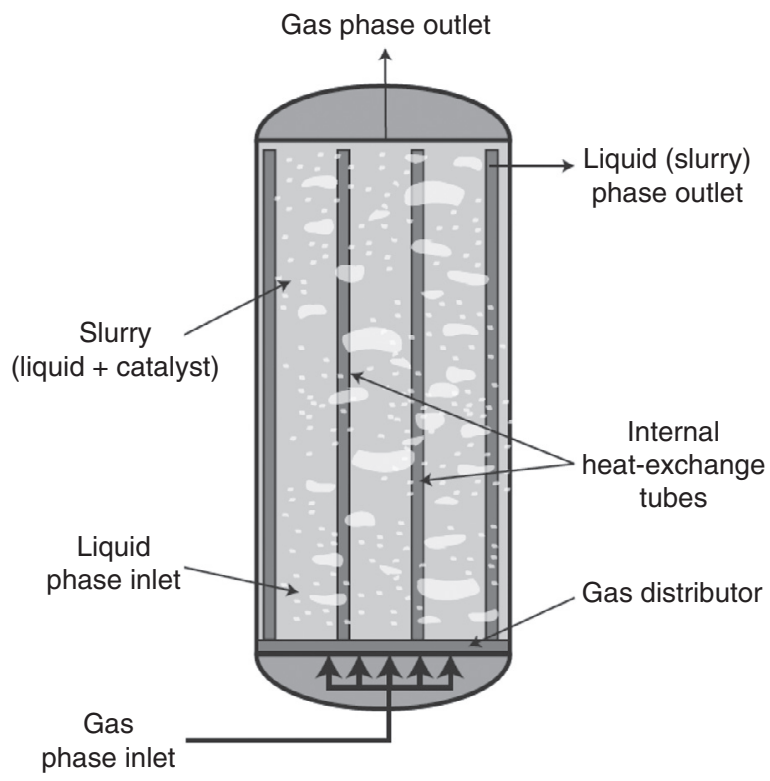

Figure 3

Slurry Bubble Column Reactor (SBCR) (from Forret et al., 2006).

TABLE 1

Fischer-Tropsch reactor comparison

\begin{tabular}{|c|c|c|}
\hline Reactor technology & SBCR & MTFBR \\
\hline \multirow[t]{3}{*}{ Catalyst } & Powder $(10-100 \mu \mathrm{m})$ & $\begin{array}{l}\text { Ball or extruded } \\
\qquad(2-3 \mathrm{~mm})\end{array}$ \\
\hline & $\mathrm{Co}$ & $\mathrm{Co}$ or $\mathrm{Fe}$ \\
\hline & Slurry & Fixed bed \\
\hline \multicolumn{3}{|l|}{$\begin{array}{l}\text { Operating } \\
\text { conditions }\end{array}$} \\
\hline Temperature $\left({ }^{\circ} \mathrm{C}\right)$ & $200-250$ & $200-250$ \\
\hline Pressure (barg) & $15-25$ & $15-25$ \\
\hline Phases & Gas - liquid - solid & Gas - liquid - solid \\
\hline Heat extraction & Bundle & Shell and tubes \\
\hline Isotherm & Very good & Medium \\
\hline Pressure drop & Low & High \\
\hline Catalyst attrition & Low to high & Very low \\
\hline $\begin{array}{l}\text { Catalyst/Product } \\
\text { separation }\end{array}$ & Settling, filtering & Natural \\
\hline Scale-up & Difficult & Easy \\
\hline $\begin{array}{l}\text { Capacity per train } \\
\text { (bpd) }\end{array}$ & 15000 & 2000 \\
\hline
\end{tabular}




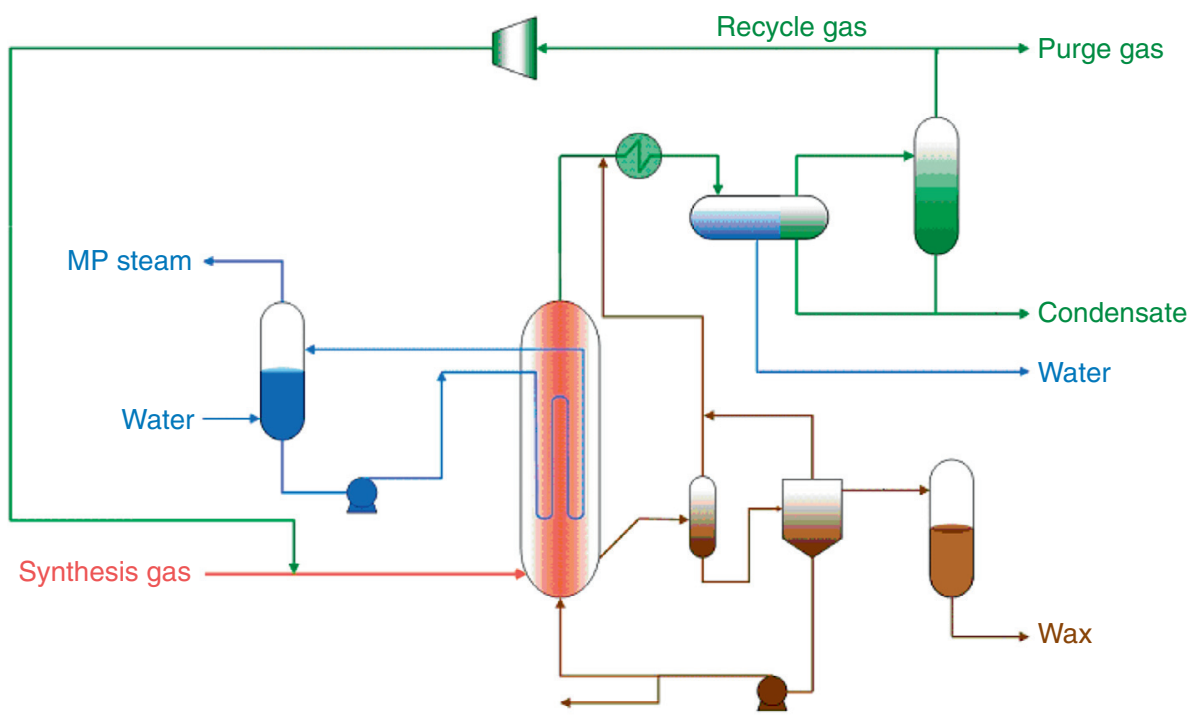

Figure 4

Fischer-Tropsch Simplified Process Scheme.

\subsection{Preliminary Process Scheme}

The FT section is composed of different process sections:

- the slurry bubble column reactor, which is the main part of the process;

- the gas/liquid separating section where the lighter products, vapors in reactor operating conditions, are separated;

- the liquid/solid separation train where higher hydrocarbons are separated from the catalyst to remove hydrocarbons and maintain the catalyst inventory inside the unit;

- the steam/water section for heat extraction.

The preliminary process scheme is presented in Figure 4.

\subsection{Key Points for Development}

The key points for FT process development are presented in Figure 5. First, as explained from Sections 1.1 to 1.3, a preliminary process engineering step will select the catalyst type and the reactor technology, a preliminary process scheme is then defined to perform an economic evaluation. If the first economics are satisfying, the development phase starts. For FT SBCR technology development, the catalyst development and chemical and process engineering are closely linked due to the impact of the catalyst on the process and vice versa. A number of complementary tools are necessary to validate each step of the development. Catalyst development requires laboratory tools for catalyst prescreening performance tests (a few hundred hours of tests) and long-life tests mandatory to predict the performance at
$8000 \mathrm{~h}$. Dedicated analysis methods are essential to quantify the FT effluent product quality and properties accurately in the field of catalyst development. Analysis methods are described in Section 2. The scale-up of the SBCR is one of the major challenges of the FT process development and requires many complementary tools on several scales $($ Sect. 3,4$)$ to predict gas holdup and liquid velocity in industrial conditions (pressure effect, superficial gas velocity effect, liquid velocity). The development and validation of a hydrodynamic model is therefore a key point for the process development in order to properly design the reactor on an industrial scale and estimate the mechanical stress that will be undergone by the catalyst in order to test the catalyst resistance in industrial conditions in a dedicated pilot tool. The slurry bubble column pilot plant is the final step of validation for the catalyst and the technology development.

Throughout the process development, process engineering will be the key for the integration of the knowledge from all the development studies in order to take into account the catalyst constraint management and various product properties. Scheme integration with process equipment technology limitations is also a challenge in slurry technology. The following sections will detail the FT technology development phase to result in the process guide technology handbook.

\section{CATALYST DEVELOPMENT}

Many of the catalysts used in the industry are designed upon the paradigm of an active phase supported on an 


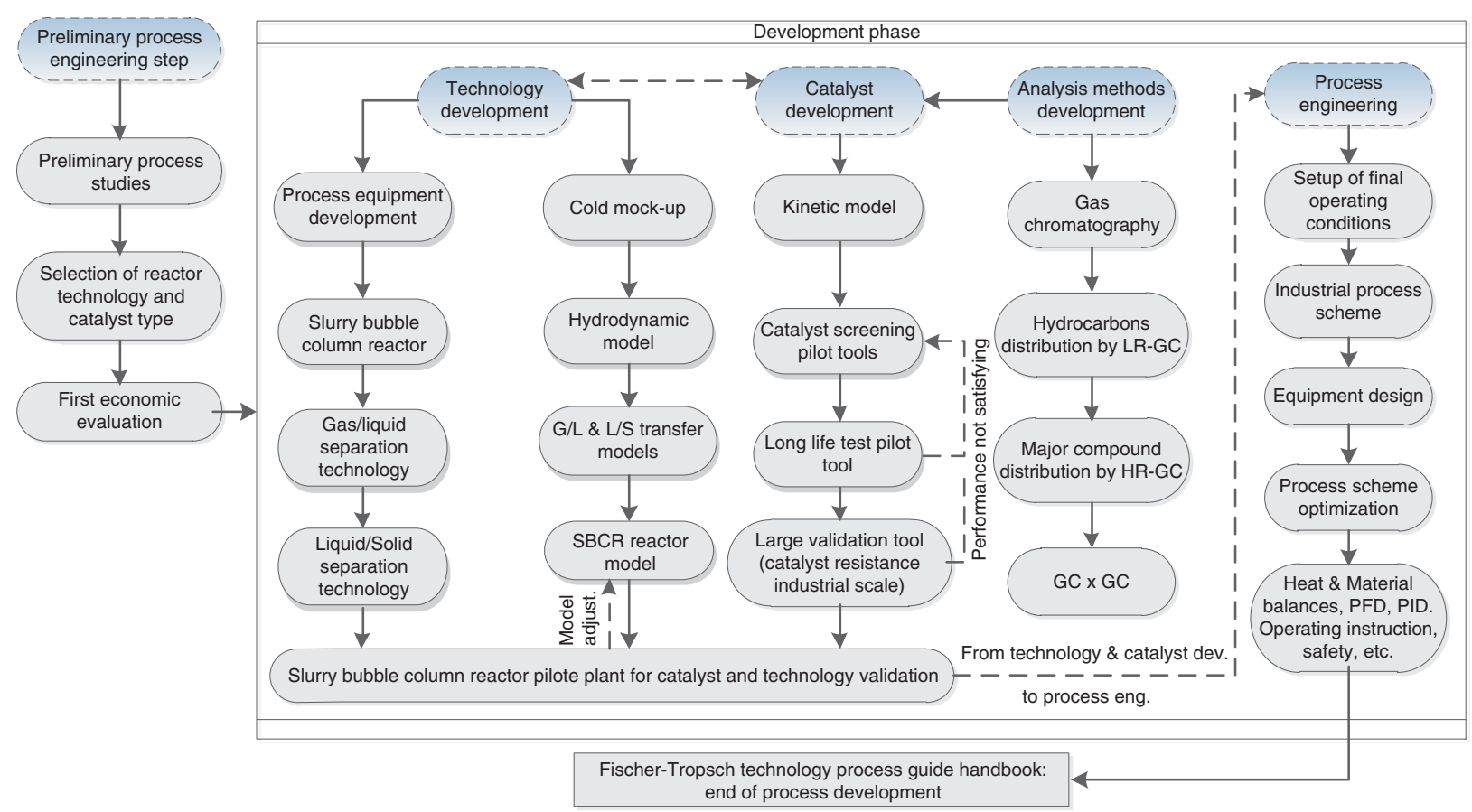

Figure 5

Fischer-Tropsch process development approach.

oxide carrier. Several decades of research and development have improved this idea (Bartholomew and Farrauto, 2006): the active phase is designed and controlled to fit the reaction and process requirements in terms of activity, selectivity and stability. The carrier properties ensure an adequate dispersion and stability of the active phase, as well as minimizing heat and mass transfer inside catalyst grains when needed. Finally, the overall solid particle can be promoted in order to improve the activity/selectivity/stability of the active phase and/or the mechanical/chemical stability of the carrier. All catalyst developments have to be performed using the appropriate catalytic test methodology that will be described.

\subsection{Catalyst Carrier}

The catalyst carrier of a FT catalyst must present a moderately high surface, porous volumes in accordance with the diffusion of large paraffin molecules, and good thermal stability to resist the thermal treatments needed for the formation of the active phase. Moreover, from an industrial point of view, the carrier must be cheap and widely available. The most preferred carrier fulfilling these criteria is probably $\gamma$-alumina. However, it has been shown that its hydrothermal resistance, a key parameter due to the several bars of water in FTS conditions, is relatively weak. Nevertheless, the carrier can be strengthened by the addition of promoters such as $\mathrm{Ni}, \mathrm{Mg}$ and $\mathrm{P}$ (Wei et al., 2001; Enger et al., 2011; Park et al., 2012; Perego et al., 2009).

\subsection{Active Phase: Preparation and Promotion}

All group VIII transition metals are active for FTS. However, the only metals which have sufficient $\mathrm{CO}$ hydrogenation activity are $\mathrm{Ni}, \mathrm{Co}, \mathrm{Fe}$ and $\mathrm{Ru}$. The choice of the active metal is driven by the origin of the synthesis gas used, the price of the active metal and the final desired products. When using coal as a carbon source, the synthesis gas obtained has a low $\mathrm{H}_{2} / \mathrm{CO}$ ratio which needs to be adjusted; therefore it can be interesting to choose a Fe-based catalyst, due to its high water-gas-shift activity, which enables increasing the $\mathrm{H}_{2} / \mathrm{CO}$ ratio. When using natural gas, the synthesis gas obtained is $\mathrm{H}_{2}$-rich and $\mathrm{Co}$ - or Ru-based catalysts are preferred. Nickel catalysts favor $\mathrm{CO}$ dissociation and are known to lead to high methane production. Moreover, at high pressures, nickel tends to form highly toxic nickel carbonyls and therefore leads to a loss of activity. Ru is the most active metal at the lowest temperatures (at $150^{\circ} \mathrm{C}$, highmolecular-weight molecules have been formed). However, its low availability does not make it a good candidate for 
industrial applications. Co is considered as the best candidate active phase; its rather high price makes it necessary to maximize the metal active surface area. This can be done by controlling its deposition on the support.

Most Co-based catalysts are prepared by incipient wetness impregnation of a Co precursor in aqueous solution on an oxide support. These precursors can be chosen among many chemicals (acetate, nitrates, carbonates, chloride) but the most commonly used is cobalt nitrate hexahydrate as its solubility is high and therefore enables the introduction of high amounts of metal (around 20\%), which is necessary for industrial applications. Moreover, nitrates are easy to remove via calcination treatments. However, cobalt nitrate's drawback is it leads to poor dispersion because of redistribution during drying or agglomeration during calcination. Many alternative calcination conditions have been studied to improve active phase dispersion: calcination under $1 \% \mathrm{NO}$ in $\mathrm{He}$ (Wolters et al., 2011) and freeze-drying (Eggenhuisen et al., 2012); however, these methods are not easily applicable industrially. The reduction of the cobalt oxide particles then leads to the active FT catalyst. Some preparation modes described in the literature involve a direct slow reduction of the dried solid with hydrogen, leading to a better dispersion and reduction degree (Iglesia, 1997; Reuel and Bartholomew, 1984). The carrier used also strongly influences the metal dispersion. High dispersions are usually a goal in order to maximize the (expensive) metal active surface area. However, small crystallites that are favored by strong metal-support interactions are harder to reduce. Alumina is again a rather good compromise as it generates intermediate supportactive phase interactions (compared with silica and titania, for example). Moreover, it has been shown in the literature that in the case of FTS, there is an optimum Co crystallite size whose value varies between 4 and $8 \mathrm{~nm}$ depending on the catalyst carrier and reaction conditions (den Breejen et al., 2010; Fischer et al., 2013). Most authors, however, agreed on the necessity to obtain a narrow particle size distribution. Different methods can be applied to reach this goal: use of organic precursor complexes, chelating ligands, colloids, optimization of drying, calcination and reduction conditions, the nature of the support (crystallographic type, textural properties), and Co deposition mode (impregnation, reverse micelle preparation, CVD).

In addition to the cobalt active phase, some promoters can be added to improve the catalyst activity, selectivity and stability (Zhang et al., 2013). Structural promoters can stabilize the support in order to avoid formation of cobalt aluminate; they can prevent the sintering of cobalt particles or can increase the dispersion and improve the reducibility of Co small particles (for instance, with promoters such as Re, Pt and Ru). These are, however, very costly metals and are used at very low concentrations (lower than $1000 \mathrm{ppm})$.

\subsection{Catalytic Validation Tests Strategy}

A catalytic test methodology for the development of an industrial catalyst should allow the assessment of a maximum amount of information about the behavior of the catalyst, in the minimum amount of time. Since the synthesis of a catalyst starts with the choice of the carrier, care must be taken to choose a carrier with good hydrothermal stability (Fig. 6). The evaluation of the hydrothermal resistance of the carrier can thus be performed in an autoclave test, in the presence of water at temperatures close to those used for FTS. The formation of fines and boehmite on the support is then monitored and compared with that of a reference support whose resistance to fine formation has been evaluated on a large scale (semi-industrial) and judged acceptable.

After the deposition of the cobalt precursor and formation of the metallic active phase by ex situ reduction, the initial activity and selectivity must be quickly assessed in order to minimize the quantity of catalysts to be studied further. This first catalytic screening can be performed using small autoclaves (several cc) with a small quantity of solid in slurry conditions, with tests no longer than a few hundred hours. The use of a small autoclave was chosen in order to work with a better homogeneity of operating conditions (temperature, water partial pressure) to simulate the slurry bubble conditions better with low attrition phenomena. After this screening phase, the more initially active and selective catalysts are selected. The next step consists of evaluating their stability (activity and selectivity) over time. This can be done by very long tests (several thousand hours) on larger autoclaves (liters) with higher catalyst volume. The catalyst reduction is carried out ex situ for both autoclave testing cases (long test and screening); the reduction degree has been shown to be the same and reproducible over time. IFPEN optimized this long stability screening phase with accelerated aging tests in small autoclaves over several hundred hours in optimized conditions. These tests include two sequences. The first one, lasting $150 \mathrm{~h}$, is performed under harsh operating conditions (pressure, conversion and temperature) to accelerate the rate of deactivation of the catalyst. For the second one, lasting 200-300 h, the operating conditions are set to standard FT conditions $\left(230^{\circ} \mathrm{C}, 20\right.$ bar, $\mathrm{H}_{2} / \mathrm{CO}=2,50 \% \mathrm{CO}$ conversion). During these sequences, the activity and selectivity of the catalyst are stabilized; no more deactivation is observed. It was shown on several different catalysts that the activity and selectivity at the end of these $300 \mathrm{~h}-400 \mathrm{~h}$ accelerated aging tests were equivalent to very long standard tests of $3000 \mathrm{~h}$ (Fig. 7). Deactivation may find its origin in several mechanisms: poisoning, 
Carriers Catalysts

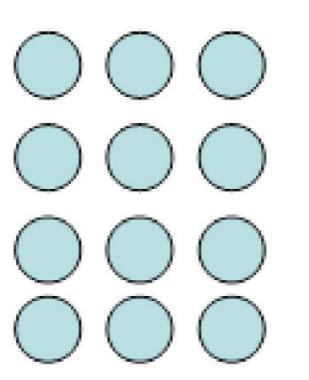

Hydrothermal test resistance to water

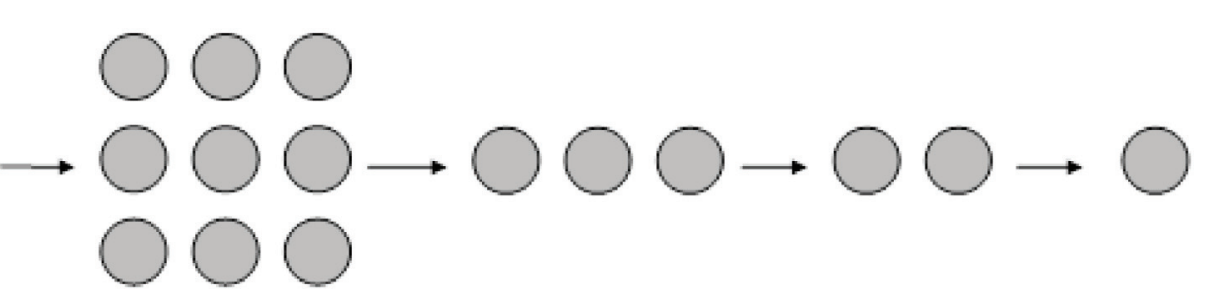

Short catalytic test initial activity and selectivity

\author{
Long catalytic test \\ accelerated aging test \\ Catalytic stability
}

Industrial catalysts
Large validation tool SBCR in demo plant

Formation of fines behavior in SBCR

Figure 6

Evolution of catalytic tests from small autoclaves to the SBCR demonstration.

attrition, sintering of the metallic active phase, oxidation, carbon deposition and reconstruction of the metallic surface (Bartholomew, 2001; Visconti et al., 2007; Peña et al., 2013, 2014). Although it is generally quite easy to detect and highlight these deactivation phenomenon separately, it is, so far, not possible to show their precise contribution to deactivation and deselectivation in real Fischer-Tropsch conditions.

At this stage, the catalyst candidates have good initial activity and selectivity, and acceptable stability over time. The last unknown information remains the mechanical stability under reactive conditions and on an industrial reactor scale (formation of fines). This information can be assessed using an autoclave reactor named a LVT, presented in Section 4.

The whole experimental strategy implemented to select and validate catalysts is described in Figure 6 with an illustration of catalysts candidate's numbers at each step.

\subsection{Analysis Methods for Fischer-Tropsch Effluents}

Screening and validating FT catalysts requires accurate analytical methods to monitor the composition of FischerTropsch effluents. Among all the techniques available, Gas Chromatography (GC) is the most suited for the analysis of these products. GC methods employed at IFPEN throughout the development of the FT process were recently reviewed by Bertoncini et al. in 2009. The gas phase produced in pilot units is directly analyzed online via the injection of the gaseous stream exiting the unit. The analytical methods used are derived from ASTM D1945 and D1946 standard methods. Thanks to an appropriate set of packed

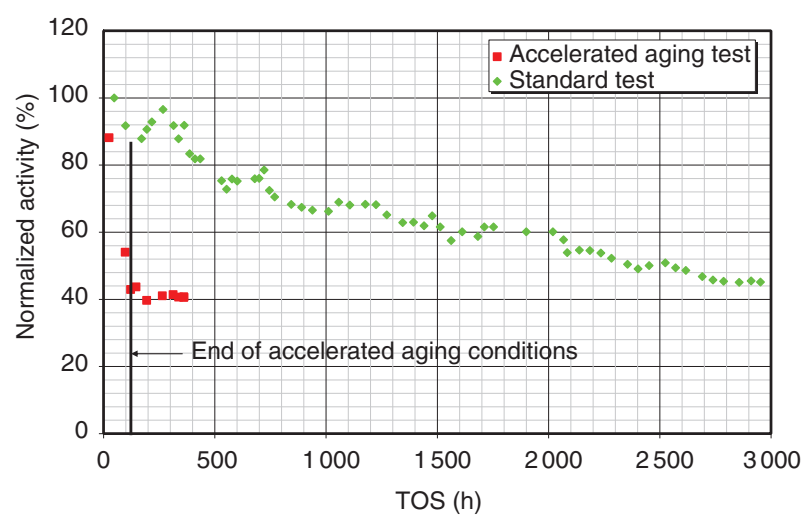

Figure 7

Compared normalized activities of a long standard test in real Fischer-Trospch conditions $\left(230^{\circ} \mathrm{C}, \mathrm{H}_{2} / \mathrm{CO}=2,20\right.$ bar, conversion $=50 \%$ ) and an accelerated test of a $20 \% \mathrm{Co}$ /alumina catalyst.

columns, valves and detectors (flame ionization detector or thermal conductivity detector), carbon monoxide, hydrogen, carbon dioxide, light hydrocarbons and olefins (less than C6) and trace amounts of light alcohols are separated and quantified.

One of the key features for FT catalysts is their selectivity (the chain length growth coefficient $\alpha$ for paraffins in the Schultz-Flory model). Selectivity is determined from the distribution of paraffins according to their carbon number. These compounds in the whole FT liquid sample are quantified with low-resolution GC methods derived from simulated distillation methods (ASTM D2887, for instance), 


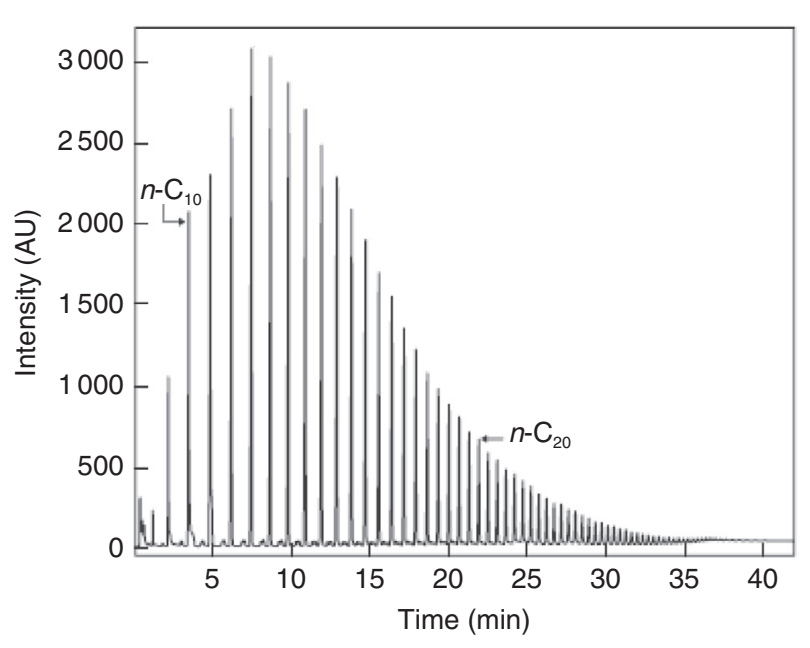

Figure 8

Typical hydrocarbon distribution in FT liquid sample by LR-GC (from Bertoncini et al., 2009).

as heavy paraffins must elute from the analytical column. Megabore capillary columns with a thin non-polar stationary phase, a high oven temperature (up to $410^{\circ} \mathrm{C}$ ) and oncolumn injection techniques are implemented. Paraffins with carbon numbers up to $n \mathrm{C} 80$ are eluted and quantified as depicted in Figure 8. Selectivities of FT catalysts are calculated from the distribution of paraffins between $n \mathrm{C} 15$ and $n \mathrm{C} 50$ with confidence intervals equal to 0.003 and 0.005 for selectivities in the range 0.88-0.9 and larger than 0.91 , respectively. However, due to the low chromatographic efficiency of these columns, separation between the main classes of compounds (paraffins, olefins and alcohols) remains unperfected and only the distribution of hydrocarbons is achieved with LR-GC.

Detailed analysis of the FT liquid phase is performed with high-resolution GC methods. Capillary columns with more theoretical plates, i.e. with smaller internal diameters and higher lengths, are used. Gaining efficiency implies, however, lowering the ability of the column to elute heavy compounds. Hence, the heavy fraction of the FT wax $(\mathrm{C} 30+$ fraction) is typically vented out to the injector by flow switching between a highly efficient analytical column and a short pre-column. As shown in Figure 9 for the C11-C13 part of the chromatogram obtained on a small ID DB-1 capillary column, HR-GC leads almost to the complete separation of the main classes of compounds ( $n$-olefins, $n$-alcohols and $n$-paraffins) in the $\mathrm{C} 30$ fraction. Distributions of all these classes of compounds according to their carbon numbers are determined and the selectivities of these Schultz-Flory distributions for each chemical family can be evaluated.

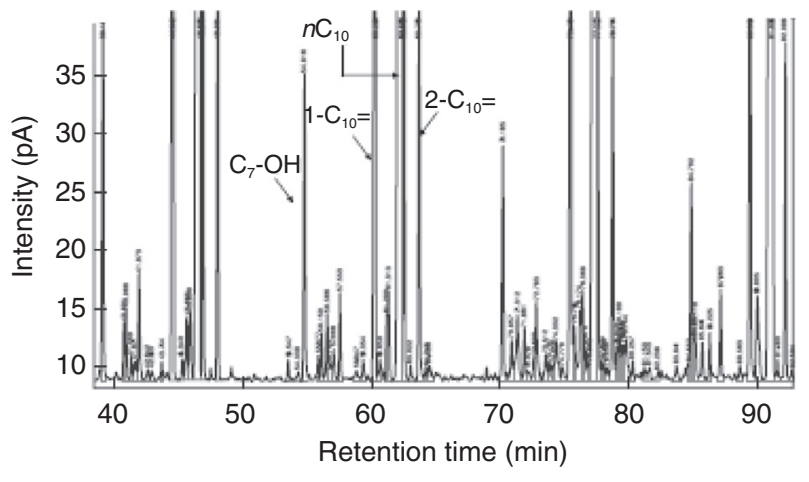

Figure 9

Characterization of linear olefins, alcohols and paraffins by HR-GC for the C11-C13 fraction (from Bertoncini et al., 2009).

Nevertheless, unraveling the nature of FT products in-depth and especially identifying trace oxygenated compounds requires even more powerful separation techniques. This can be achieved by implementing comprehensive twodimensional Gas Chromatography $(\mathrm{GC} \times \mathrm{GC}) . \mathrm{GC} \times \mathrm{GC}$ consists of coupling two GC columns with complementary retention mechanisms through a modulation device. Each compound eluting from the first column is refocused by the modulator and reinjected in narrow bands into the second column which is connected to the detector. The $\mathrm{GC} \times \mathrm{GC}$ technique is able to overcome the limitations of HR-GC by increasing the peak capacities provided by each dimension of separation, by increasing sensitivity due to the refocusing of analytes at the outlet of the first column and thus facilitating identification of the family-structured $2 \mathrm{D}$ chromatograms obtained. $\mathrm{GC} \times \mathrm{GC}$ in a classical non-polar/ semi-polar configuration hyphenated with mass spectrometry evidences the formation of oxygenated compounds at trace levels such as methyl esters, linear and branched aldehydes, ketones, and carboxylic acids in the Co-catalyzed FT reaction. Quantification of these compounds is achieved with a FID by taking into account response factors for oxygenates. Inverse $\mathrm{GC} \times \mathrm{GC}$ configurations (polar/non-polar) also demonstrated their usefulness in separating oxygenates from hydrocarbons in FT products (van der Westhuizen et al., 2010) and are used at IFPEN. To go deeper into the characterization of FT products, this kind of $\mathrm{GC} \times \mathrm{GC}$ configuration has recently been hyphenated with online supercritical fluid chromatography by Potgieter et al. (2013) to comprehensively characterize the chemical families in FT samples (saturates, unsaturates, oxygenates and aromatics) in one analysis.

FT samples are highly complex mixtures containing many different chemical families, but the combination of several 
TABLE 2

Physical properties of various gas-liquid systems in ambient conditions and expected wax properties in industrial operating conditions

\begin{tabular}{c|c|c|c|c|c}
\hline \multirow{2}{*}{ Ambient conditions } & & $\begin{array}{c}\text { Temperature } T \\
(\mathrm{~K})\end{array}$ & $\begin{array}{c}\text { Density } \rho_{L} \\
\left(\mathrm{~kg} / \mathrm{m}^{3}\right)\end{array}$ & $\begin{array}{c}\text { Dynamic viscosity } \mu_{L} \\
(\mathrm{mPa} . \mathrm{s})\end{array}$ & $\begin{array}{c}\text { Surface tension } \sigma \\
(\mathrm{N} / \mathrm{m})\end{array}$ \\
\cline { 2 - 6 } & Air-water & 293 & 1000 & 1 & 0.073 \\
\hline \multirow{2}{*}{ Industrial conditions } & Nitrogen-heptane & 293 & 690 & 0.41 & 0.020 \\
& Paraffin wax & 493 & 690 & 4.0 & 0.024 \\
\hline
\end{tabular}

GC methods from low-resolution GC to extremely powerful $\mathrm{GC} \times \mathrm{GC}$ allows the quantification of these compounds. All these techniques are implemented at IFPEN and are mandatory to evaluate the FT catalyst activities and selectivities. They help in the design of more efficient catalysts but are also precious tools for better understanding of FT reaction mechanisms.

\section{TECHNOLOGY DEVELOPMENT: SCALE-UP OF SLURRY BUBBLE REACTOR}

\subsection{Strategy for Scale-Up}

The reactor performance and volumetric productivity and selectivity are significantly affected by the fluid dynamics. Since slurry bubble columns are operated with a liquid superficial velocity lower than the gas superficial velocity by at least an order of magnitude, the gas flow controls the two-phase flow dynamics. The gas flow generates liquid recirculation and mixing and controls interface mass transfer, and subsequently controls temperature gradients inside the reactor, and finally reaction conversion and selectivity. Moreover, liquid recirculation may induce catalyst attrition and internal abrasion. Therefore, reliable design and scaleup of the reactor requires accurate information on hydrodynamics. For industrial reactor scale-up purposes, the global approach of the "plug flow - dispersion" model is used, as well as phenomenological models. For these models, the following global characteristics should be determined: overall gas holdup, centerline liquid velocity and axial dispersion coefficient, Dax that characterizes the degree of liquid mixing. These characteristics thus have to be measured as a function of scale and in the presence or not of reactor internals. As explained in Section 3.3.2, when reactor internals are implemented (heat exchange coils), the one-dimensional axial dispersion model is no longer appropriate and a twodimensional (2-D) model was therefore developed (Forret et al., 2006) to account for the radial dependence of the axial velocity, axial dispersion (Dax, 2D) and radial dispersion (Drad, 2D). In a further step, CFD could be quite relevant in order to simulate effects of reactor geometry (such as the disengagement zone, heat-exchanger headers, etc.). Nevertheless, because of a lack of local experimental data (such as bubble size and velocity), it is still difficult to properly validate closure laws in the CFD model to use it in a predictive way.

\subsection{Experimental Approach}

\subsubsection{Fluid Systems}

Effects of slurry properties should be taken into account to scale up hydrodynamics from the laboratory unit to industrial reactors. Fluids used in the laboratory unit in ambient conditions (water and heptane) are chosen to reproduce the main fluid properties (density, viscosity and surface tension) of standard Fischer-Tropsch wax in industrial conditions. Table 2 reports the physical properties of laboratory gas-liquid systems at ambient temperature and pressure, and the standard FischerTropsch wax properties in industrially relevant operating conditions (Bukur et al., 1987; Patel et al., 1990).

\subsubsection{Experimental Tools}

To determine the sensitivity of hydrodynamic characteristics to the column diameter and to be able to predict their order of magnitude on a large scale, measurements should be performed in different column sizes and with diameters as large as possible with respect to experimental constraints. At IFPEN several columns have been implemented with increasing diameters: $0.15,0.40$ and $1 \mathrm{~m}$. To be as close as possible to industrial conditions and to simulate the presence of vertical cooling tubes, internals were inserted into the 1-m-diameter bubble column, with the following configuration: 56 tubes with an external diameter of $63 \mathrm{~mm}$, arranged in a square pitch of $108 \mathrm{~mm}$.

\subsubsection{Measuring Techniques}

To determine the hydrodynamic characteristics in a bubble column, the following technical means were implemented:

- the visual technique is used to measure the global gas holdup by measuring the liquid level with and without gas flow; 


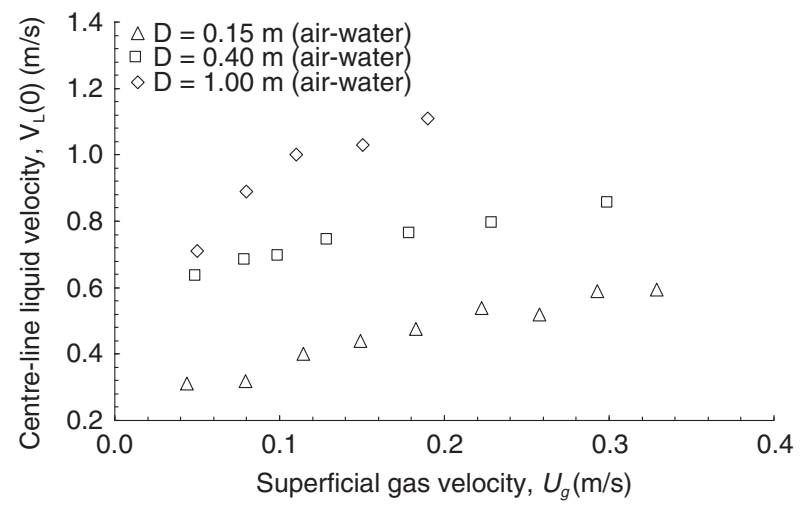

Figure 10

$V_{L}(0)$ as a function of $U_{g}$ for $D=0.15,0.40$ and $1 \mathrm{~m}$.

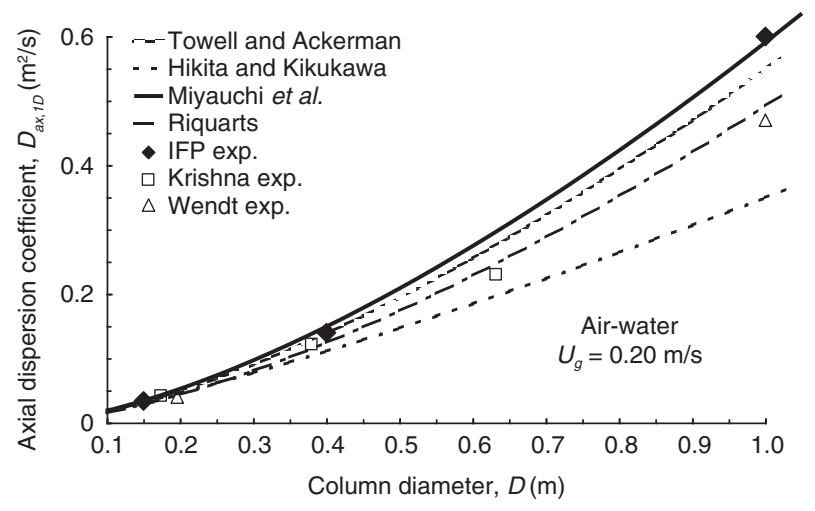

Figure 11

$D_{a x, 1 D}$ as a function of $D$ compared with empirical correlations.
- the liquid velocity $V_{L}$ and fluctuation of the velocity are measured by a modified Pavlov tube (Forret et al., 2003). The measured liquid velocity with the Pavlov tube is reliable within an error of $10 \%$, which is quite reasonable up to a gas holdup of $25 \%$;

- for the determination of the liquid phase residence time distribution, a solution of potassium nitrate $\mathrm{KNO}_{3}$ is used as a tracer (Forret et al., 2006). The solution was injected into the batch liquid phase above the aerated height. Tracer evolution in the column is followed by conductivity measurement, conductivity values being directly proportional to tracer concentration. To avoid problems of in situ conductivity measurement, samples are taken every second at the same height and at two radial positions (one in the middle of the up flow liquid flow region, the other in the middle of the down flow liquid flow region).

\subsection{Experimental Results}

\subsubsection{Flow Structure with Scale Effect}

Let us first consider gas holdup as a function of superficial gas velocity $U_{g}$ for three column diameters using the air-water system with an aerated height to diameter ratio $H_{D} / D$ greater than 5. Global gas holdups obtained in the columns of $0.4 \mathrm{~m}$ and $1 \mathrm{~m}$ diameter are quite similar, and slightly different from the column of $0.15 \mathrm{~m}$ diameter at low gas velocity. In fact, in columns of smaller diameter than $0.15 \mathrm{~m}$ with an air-water system, the wall effect cannot be totally neglected. Thus, for $D>0.15 \mathrm{~m}$, the global gas holdup is independent of scale.

The centerline liquid velocity (maximum liquid velocity measured) $V_{L}(0)$ as a function of $U_{g}$ for different diameters is shown in Figure 10. As one can see, $V_{L}(0)$ increases strongly with scale. For operation at $U_{g}=0.20 \mathrm{~m} / \mathrm{s}$, it can be noted that $V_{L}(0)$ is higher than $1 \mathrm{~m} / \mathrm{s}$ in the column of $1 \mathrm{~m}$ diameter, which is more than twice the value obtained in the column of $0.15 \mathrm{~m}$ diameter.

\subsubsection{Liquid Mixing with Scale and Internals Effects}

To complete the study of the liquid flow pattern, let us compare the results obtained in the 1-m-diameter column concerning the axial dispersion coefficient $D_{a x, 1 D}$, obtained relating to the well-known mono-dimensional axial dispersion model. For each superficial gas velocity, three dual samplings were performed for three different distances between the sampling position and the free surface. Tracer experiments were performed in columns of 0.15 , 0.4 and $1 \mathrm{~m}$ diameter to determine axial dispersion coefficients. Figure 11 shows $D_{a x, 1 D}$ as a function of $D$ at $U_{g}=0.20 \mathrm{~m} / \mathrm{s}$. Analogous to $V_{L}(0)$ (Fig. 10), the axial dispersion coefficient is found to increase strongly with column diameter. Figure 11 compares our experimental results with correlations proposed in the literature and experimental data obtained by Wendt et al. (1984) and Krishna et al. (1999). The most relevant empirical correlation appeared to be the one proposed by Miyauchi et al. (1981); see Forret et al. (2006).

In the presence of reactor internals, large-scale recirculation is enhanced and the axial liquid velocity increases in the core of the bed, the radial liquid velocity being negligible. Moreover, the presence of internals leads to a decrease in the fluctuation of the velocity. The maximum of the fluctuations of velocity is found at the inversion flow $(r / R=0.7)$. Modification of the liquid recirculation pattern in the 
presence of internals leads to a change in liquid mixing. Indeed, liquid mixing is a result of global convective recirculation of the liquid phase induced by the non-uniform gas radial holdup distribution, and of the turbulent dispersion due to the eddies generated by the rising bubbles (Degaleesan et al., 1997). Since the large-scale recirculation contribution to liquid backmixing is enhanced with internals, the one-dimensional axial dispersion model, validated without internals, is no longer appropriate to simulate large bubble columns with internals. A two-dimensional (2-D) model was therefore developed (Forret et al., 2006) to account for the radial dependence of the axial velocity (large-scale recirculation), axial dispersion $\left(D_{a x, 2 D}\right)$ and radial dispersion $\left(D_{\text {rad }, 2 D}\right)$.

\section{STRATEGY TO VALIDATE THE CATALYST AND PROCESS ON AN INDUSTRIAL SCALE}

To fully validate the process and catalyst developed and be confident in its reliable scale-up before its industrialization, two different tools were designed and implemented by IFPEN/ENI/Axens:

- a pilot plant of a capacity of $20 \mathrm{bpd}$. This pilot plant was implemented on the ENI refinery site of Sannazzaro in Italy (SNZ). The main objectives were to validate catalyst performances (activity and selectivity) in real slurry bubble conditions and on a long-term basis, to validate the different liquid/solid separation technologies, and slurry catalyst handling. This pilot plant has allowed the operation of a slurry bubble column in FT conditions for more than $20000 \mathrm{~h}$ since 2001;

- a LVT in order to quantify fine formation on the catalyst on an industrial scale and to demonstrate the mechanical resistance in a real industrial reactor of large size. This tool is composed of a Continuous Stirring Tank Reactor (CSTR) of large volume that has been designed in order to simultaneously reproduce the real mechanical stress that the catalyst will undergo on an industrial scale (up to $15000 \mathrm{bpd}$ ) and the chemical environment of the catalyst during the FT synthesis process.

The hydrodynamic model based on experiments on different reactor scales (from 20 to $1000 \mathrm{bpd}$ ) with and without reactor internals (Sect. 3) was used for data to determine the actual slurry recirculation velocity as a function of the reactor diameter (Schweitzer and Viguié, 2009). It was thus possible to estimate the real maximum liquid velocity and the corresponding shear stress that will occur in an industrial reactor for a maximum diameter of $10 \mathrm{~m}$ (corresponding to a capacity of $15000 \mathrm{bpd})$. Then, the LVT autoclave reactor was designed (reactor size and internal) in order to reproduce the shear stress of an industrial reactor from 0.4 up to $10 \mathrm{~m}$ in diameter. By performing tests in FT conditions over a long

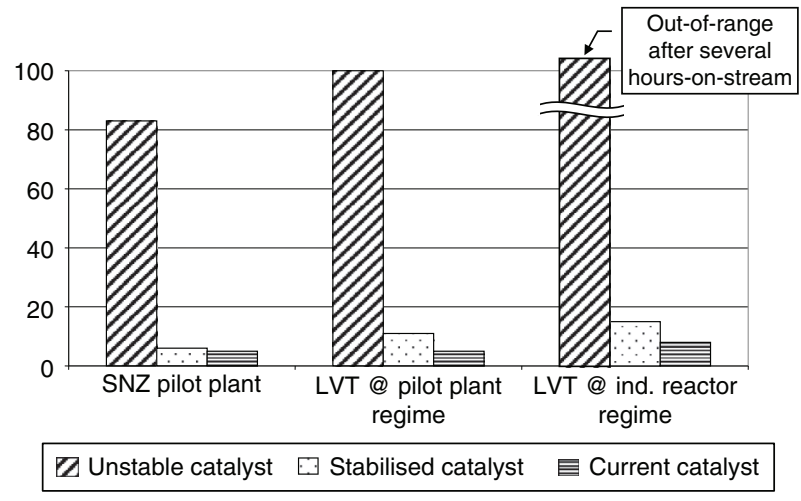

Figure 12

Relative rate of fines formation for three different catalysts, as obtained in the Sannazzaro slurry bubble column pilot plant and in the LVT.

time period on this unit it is possible to determine the fine particle formation over time with reproduced real reacting and mechanics conditions. The fine formation is estimated by determining the fine amount inside a small amount of sampled slurry waxes. This unit design was first validated by correctly reproducing the fine formation observed in a SNZ pilot unit of $20 \mathrm{bpd}$ with the same shear stress. Then, it was possible to estimate the fine production on an industrial scale of a 10 -m-diameter reactor by performing a test with the developed catalyst increasing the shear stress up to the industrial one predicted by the hydrodynamic model. It was thus possible to estimate fine production on an industrial scale for different catalysts, as shown in Figure 12.

\section{SIMULATION OF THE FISCHER-TROPSCH UNIT}

The objective of the reactor model is to predict the performances of an industrial Fischer-Tropsch process including all the scale-up rules for hydrodynamics and transfers. A first model was already developed by Schweitzer and Viguié (2009). A new model version was developed including alcohol formation and a micro-kinetic description based on Visconti et al. (2011) mechanism for paraffin and olefin production. The aim of this new kinetic model is to be able to predict selectivity (paraffin and olefin distributions) forvarious operating conditions (pressure, temperature, GHSV (Gas Hourly Space Velocity) and $\mathrm{H}_{2} / \mathrm{CO}$ ). The new simulator is able to plug both kinetic models:

- one based on Sarup and Wojciechowski (1989) description for $\mathrm{CO}$ conversion with an imposed selectivity for paraffins and olefins using an Anderson-Schultz-Flory distribution; 
- one based on Visconti's mechanism where the selectivity is predicted.

The first kinetic model is an empirical approach where only CO conversion is predicted. Then, it is necessary to combine a selectivity model based on the AndersonSchultz-Flory distribution. This distribution is based on a chain length growth parameter which is dependent on operating conditions. The new kinetic model is based on elementary reactions occurring on the catalyst surface. In this model, no apparent rate law expression is needed. Paraffin and olefin selectivities are deduced from the kinetic model (no fitted chain length growth parameters).

\subsection{Fischer-Tropsch Micro-Kinetic Model (Visconti et al., 2011)}

The reaction mechanism is similar to a polymeric kinetic process. It consists of several steps: as a first step, dissociative adsorption of $\mathrm{H}_{2}$ and non-dissociative adsorption of $\mathrm{CO}$ are considered:

$$
\begin{gathered}
\mathrm{H}_{2} \text { dissociative adsorption } \mathrm{H}_{2}+2^{*} \leftrightarrow 2 \mathrm{H}^{*} \\
\text { CO non dissociative adsorption } \mathrm{CO}+{ }^{*} \leftrightarrow \mathrm{CO}^{*}
\end{gathered}
$$

Then, adsorbed $\mathrm{CO}$ can react with adsorbed hydrogen to form adsorbed $\mathrm{HCO}$ as follow:

$$
\mathrm{CO}^{*}+\mathrm{H}^{*} \leftrightarrow \mathrm{HCO}^{*}+{ }^{*}
$$

Adsorbed methylene and water are formed thanks to a set of fast consecutive reactions:

$$
\begin{gathered}
\mathrm{HCO}^{*}+\mathrm{H}^{*} \rightarrow \mathrm{HCOH}^{*}+{ }^{*} \\
\mathrm{HCOH}^{*}+{ }^{*} \rightarrow \mathrm{CH}^{*}+\mathrm{OH}^{*} \\
\mathrm{CH}^{*}+\mathrm{H}^{*} \rightarrow \mathrm{CH}_{2}^{*}+{ }^{*} \\
\mathrm{OH}^{*}+\mathrm{H}^{*} \rightarrow \mathrm{H}_{2} \mathrm{O}+2^{*} \\
\mathrm{HCO}^{*}+3 \mathrm{H}^{*} \rightarrow \mathrm{CH}_{2}^{*}+\mathrm{H}_{2} \mathrm{O}+3^{*}
\end{gathered}
$$

Then, an initiator is formed:

$$
\mathrm{CH}_{2}^{*}+\mathrm{H}^{*} \rightarrow \mathrm{CH}_{3}^{*}+{ }^{*}
$$

The propagation consists of the insertion of adsorbed methylene:

$$
R_{n}^{*}+\mathrm{CH}_{2}^{*} \rightarrow R_{n+1}^{*}+{ }^{*} \text { for } n=1 \text { to } 49
$$

Termination reactions lead to paraffin and olefin formations:

$$
R_{n}^{*}+\mathrm{H}^{*} \rightarrow P_{n}+2^{*} \text { for } n=2 \text { to } 50
$$

$$
\begin{gathered}
\mathrm{CH}_{3}^{*}+\mathrm{H}^{*} \rightarrow \mathrm{CH}_{4}^{*}+2^{*} \\
R_{n}^{*} \leftrightarrow \mathrm{O}_{n}+\mathrm{H}^{*} \text { for } n=3 \text { to } 50 \\
\mathrm{C}_{2} \mathrm{H}_{5}^{*} \leftrightarrow \mathrm{C}_{2} \mathrm{H}_{4}+\mathrm{H}^{*}
\end{gathered}
$$

Only a limited number of kinetic parameters are able to describe the overall kinetic rates of this reaction network (Tab. 3).

Formation of alcohols is not predicted by the microkinetic model. Alcohol formation was implemented in the model according to the following global stoichiometric reaction:

$$
\mathrm{CO}+2 \mathrm{H}_{2}=\frac{1}{n} \mathrm{C}_{n} \mathrm{H}_{2 n+2} \mathrm{O}+\frac{n-1}{n} \mathrm{H}_{2} \mathrm{O}
$$

The kinetic rate has the same formalism as the kinetic model developed by Sarup and Wojciechowski (1989), which considers a rate-determining step (first hydrogen addition to carbon). Alcohol selectivities are determined using an Anderson-Schultz-Flory distribution adjusting a corresponding chain length growth parameter. Only two parameters are fitted to simulate alcohol amount and their distribution (the kinetic constant and chain length growth parameter). Figure 13 shows an experimental validation of the corresponding approach.

\subsection{Hydrodynamics and Transfer}

\subsubsection{Liquid Hydrodynamics}

The mixing of the liquid phase plays an important role on the reactor thermal gradient which can induce a change in reactor performances. Due to the complexity of the reactor model, a simplified description of liquid hydrodynamics is made based on an axial dispersion model. This axial dispersion coefficient is correlated with the average liquid centerline velocity obtained from a 1D hydrodynamic model developed for slurry bubble columns for various column diameter and heat exchanger designs. A correlation for the liquid axial dispersion coefficient was developed as a function of the column diameter and average liquid centerline velocity (Eq. 1). This coefficient is then used in an axial dispersion model for the liquid phase:

$$
D_{a x, 1 D}=V_{L}(0) \cdot[0.2 \cdot D+0.73]-0.37
$$

\subsubsection{Gas Hydrodynamics}

The average gas flow pattern in the slurry bubble column is considered to be close to plug flow (radioactive 
TABLE 3

Kinetic parameters

\begin{tabular}{c|c|c|c|c|c}
\hline & & $K_{\text {direct }}$ & $K_{\text {reverse }}$ & $E_{\text {a,direct }}$ & $E_{\text {a,reverse }}$ \\
\hline $\mathrm{H}_{2}+2^{*} \Longleftrightarrow 2 \mathrm{H}^{*}$ & $\mathrm{H}_{2}$ absorption & $\mathrm{X}$ & $\mathrm{X}$ & $\mathrm{X}$ \\
\hline $\mathrm{CO}+{ }^{*} \Longleftrightarrow \mathrm{CO}^{*}$ & $\mathrm{CO}$ absorption & $\mathrm{X}$ & $\mathrm{X}$ & $\mathrm{X}$ & $\mathrm{X}$ \\
\hline $\mathrm{CO}+\mathrm{H}^{*} \Longleftrightarrow \mathrm{HCO}^{*}+{ }^{*}$ & $\mathrm{HCO}^{*}$ generation & $\mathrm{X}$ & $\mathrm{X}$ & $\mathrm{X}$ \\
\hline $\mathrm{HCO}+3 \mathrm{H}^{*} \rightarrow \mathrm{CH}_{2}^{*}+\mathrm{H}_{2} \mathrm{O}+3^{*}$ & $\mathrm{CH}_{2}{ }^{*}$ generation & $\mathrm{X}$ & & \\
\hline $\mathrm{CH}_{2}^{*}+\mathrm{H}^{*} \rightarrow \mathrm{CH}_{3}^{*}{ }^{*}$ & $\mathrm{CH}_{3}{ }^{*}$ generation & $\mathrm{X}$ & & \\
\hline$R_{n}^{*}+\mathrm{CH}_{2}^{*} \rightarrow R_{n+1}^{*}+{ }^{*}$ & $\mathrm{Propagation}_{n}$ & $\mathrm{X}$ & & \\
\hline$R_{n}^{*}+\mathrm{H}^{*} \rightarrow P_{n}+2^{*}$ & Paraffins generation & $\mathrm{X}$ & & \\
\hline $\mathrm{CH}_{3}^{*}+\mathrm{H}^{*} \rightarrow \mathrm{CH}_{4}+2^{*}$ & Methane generation & $\mathrm{X}$ & $\mathrm{X}$ & \\
\hline$R_{n}^{*} \Longleftrightarrow \mathrm{O}_{n}+\mathrm{H}^{*}$ & Olefins generation & $\mathrm{X}$ & & \\
\hline $\mathrm{C}_{2} \mathrm{H}_{5}^{*} \Longleftrightarrow \mathrm{C}_{2} \mathrm{H}_{4}+\mathrm{H}^{*}$ & Ethylene generation & $\mathrm{X}$ & & \\
\hline
\end{tabular}

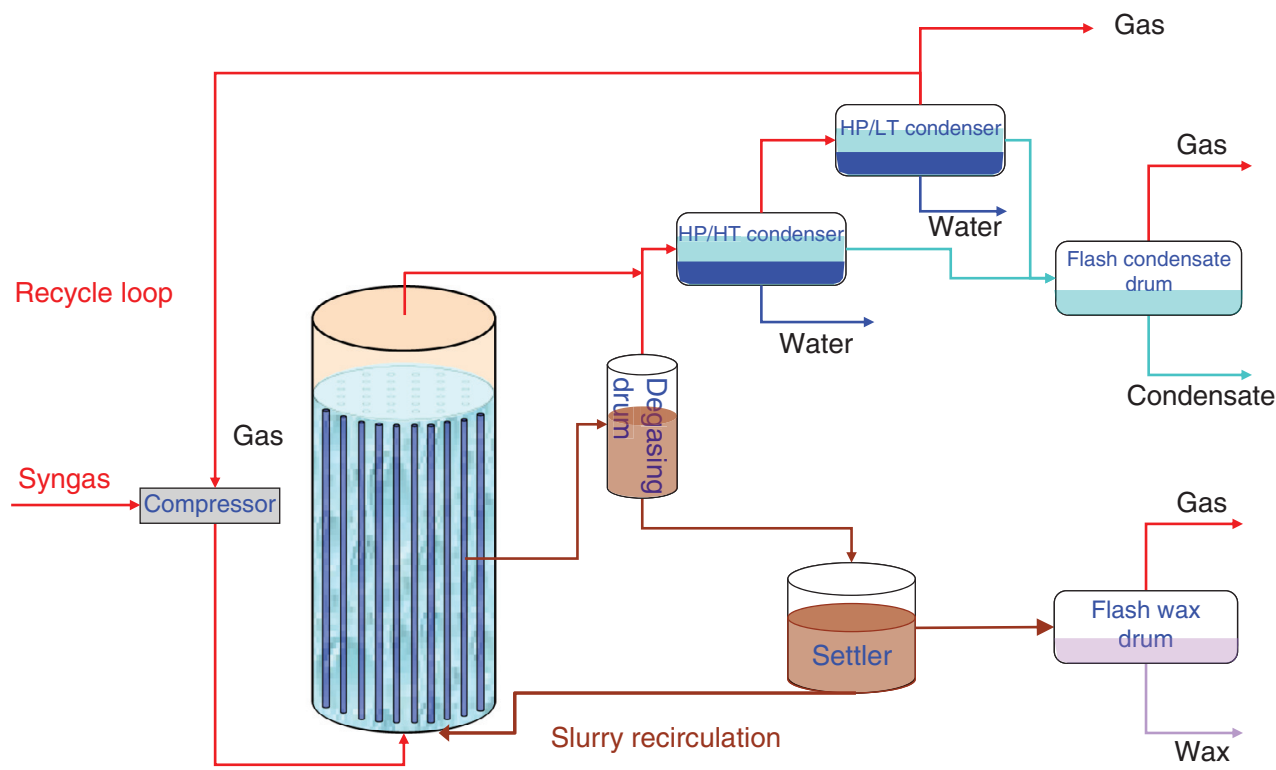

Figure 13

Process scheme around the reactor.

tracer test: Peclet number around 10 for $v_{s g}=20 \mathrm{~cm} / \mathrm{s}$ in a $1 \mathrm{~m}$ column diameter). The model for the average gas holdup is based on the Krishna approach (Krishna and Ellenberger, 1996; Krishna et al., 2000) and was already used by Schweitzer and Viguié (2009) in the former reactor model.

\subsubsection{Gas/Liquid Mass Transfer}

There are a lot of correlations in the literature, which give different values of $k_{L} \cdot a$. According to this wide range of prediction, it was decided to take the same value of $k_{L} \cdot a$ for $\mathrm{CO}$ and $\mathrm{H}_{2}$. The $k_{L} \cdot a$ value used was fixed at $0.6 \mathrm{~s}^{-1}$ that 
corresponds to an averaged value determined from the numerous literature correlations (Charpentier, 1981; Albal et al., 1984) and validated by experiments on our higherscale cold mockup.

\subsection{Reactor Material Balances in Gas and Liquid and Solid Phases}

A material balance is written for all species which are adsorbed on the catalyst surface:

$$
\frac{\partial c_{i}^{*}}{\partial t}=\sum_{j} \mu_{i, j} \cdot r_{j}
$$

This equation is written for 55 adsorbed species: $\mathrm{H}^{*}$, $\mathrm{CO}^{*}, \mathrm{HCO}^{*}, \mathrm{CH}_{2}{ }^{*}, \mathrm{O}^{*}, \mathrm{R}_{n}^{*}$ ( $n=1$ to 50 ).

Gas and liquid material balances are written for compounds which are involved in the gas/liquid mass transfer limitations (5 species: $\mathrm{CO}, \mathrm{H}_{2}, \mathrm{H}_{2} \mathrm{O}$ and $\mathrm{CO}_{2}$ ). No liquid-solid mass transfer limitations (high slip velocity) or intraparticle diffusional limitations (small particle size $<100 \mu \mathrm{m}$ ) are considered:

- gas material balances (plug flow model with G/L mass transfer):

$$
\frac{\partial\left(\frac{\varepsilon_{g}}{v_{s g}} \cdot F_{i}^{g}\right)}{\partial t}=-\frac{\partial F_{i}^{g}}{\partial z}-k_{L} \cdot a \cdot S_{r}^{e q} \cdot\left(1-\varepsilon_{g}\right) \cdot\left(\frac{P_{i}}{H_{i}}-C_{i}^{l}\right)
$$

- liquid material balances (dispersed plug flow model with $\mathrm{G} / \mathrm{L}$ mass transfer):

$$
\begin{aligned}
\varepsilon_{l} \cdot \frac{\partial C_{i}^{l}}{\partial t}= & D_{a x} \cdot \frac{\partial}{\partial z}\left(\varepsilon_{l} \cdot \frac{\partial C_{i}^{l}}{\partial z}\right)-\frac{\partial\left(v_{s l} \cdot C_{i}^{l}\right)}{\partial z} \\
& +k_{L} \cdot a \cdot\left(1-\varepsilon_{g}\right) \cdot\left(\frac{P_{i}}{H_{i}}-C_{i}^{l}\right)+\sum_{j} \mu_{i j} \cdot r_{j} \cdot \rho_{s} \cdot \varepsilon_{S}
\end{aligned}
$$

All other FT products (50 paraffins, 49 olefins, 30 alcohols) are considered to be in gas-liquid equilibrium. Only an overall material balance is written for each product:

$$
\frac{\partial F_{i}^{t o t}}{\partial z}=\beta \cdot x_{i}^{t o t} \cdot r_{1} \cdot \rho_{s} \cdot \varepsilon_{s} \cdot S_{r}^{e q}
$$

A Soave-Redlich-Kwong equation of state is used for the gas-liquid partition coefficients.

\subsection{Reactor Heat Balance}

Due to the high level of turbulence, the effective thermal conductivity is correlated with the liquid dispersion.
Therefore, thermal and material Peclet numbers have the same order of magnitude. Then, the effective thermal conductivity can be deduced assuming these Peclet numbers are equals (Eq. 6):

$$
\begin{gathered}
P e_{M}=\frac{\left(v_{s l}+v_{s s}\right) \cdot H}{D_{a x}}, \\
P e_{T}=\frac{\rho_{\text {slurry }} \cdot C_{p_{s l u r y}} \cdot\left(v_{s l}+v_{s s}\right) \cdot H}{\lambda_{a x}}, \\
P e_{M}=P e_{T} \Rightarrow \lambda_{a x}=\rho_{\text {slurry }} \cdot C_{p_{\text {slury }}} \cdot D_{a x}
\end{gathered}
$$

In the heat balance, the contribution of the gas phase is neglected. A part of the heat generated by the reaction is transferred through a tubular heat exchanger located in the slurry bubble column (Eq. 7):

$$
\begin{aligned}
\rho_{\text {slurry }} & C_{p_{\text {slury }}} \cdot\left(1-\varepsilon_{g}\right) \cdot \frac{\partial T}{\partial t}=\lambda_{a x} \cdot \frac{\partial}{\partial z}\left(\left(1-\varepsilon_{g}\right) \cdot \frac{\partial T}{\partial z}\right) \\
& -\rho_{\text {slurry }} \cdot C_{p_{\text {slury }}} \cdot\left(v_{s l}+v_{s s}\right) \cdot \frac{\partial T}{\partial z} \\
& +\sum_{j} \varepsilon_{s} \cdot \rho_{s} \cdot r_{j} \cdot\left(-\Delta H_{j}\right)-U \cdot a_{w} \cdot\left(T-T_{\text {cool }}\right)
\end{aligned}
$$

\subsection{Process Modeling}

The process scheme around the slurry bubble reactor is also simulated and included in the unit simulator. There are two recycle circuits around the reactor: one for the gas phase and one for the slurry (Fig. 13). The gas is recycled after two separation stages. In the high-temperature condenser, a two-phase flash calculation is done using the SoaveRedlich-Kwong (SRK) equation of state.

The resolution of the gas/liquid equilibrium requires values of partition coefficients relative to each compound. These coefficients were determined using the SRK equation of state for different compositions and operating conditions. It was shown that the composition does not strongly affect these coefficients. Then, correlations were developed as a function of the operating conditions using an Antoine expression (Schweitzer and Viguié, 2009). The general form of these correlations is:

$$
\begin{gathered}
\log _{10}\left(P_{t} \cdot K_{i}\right)=\frac{a_{i}}{T}+b_{i} \\
\text { with } K_{i}=\frac{y_{i}}{x_{i}}, P_{t} \text { in bar, } T \text { in } \mathrm{K}
\end{gathered}
$$

In the low-temperature condenser, a three-phase flash calculation is necessary to predict the composition of gas, hydrocarbon and aqueous phases. Partition coefficients between the liquid organic phase and the aqueous phase are given by Schantz and Martire (1987). This calculation is performed in the gas condenser HP/HT and in the gas condenser HP/LT. A rigorous three-phase flash calculation is done, 
taking into account the liquid-liquid partition coefficients for the alcohols:

$$
\begin{aligned}
x_{i}^{\text {water }}= & \frac{z_{i}}{\alpha_{\text {water }}+\alpha_{H C} \cdot K_{i}^{w / H C}+\alpha_{\text {gas }} \cdot K_{i}^{w / H C} \cdot K_{i}^{H C / \text { gas }}} \\
& x_{i}^{H C}=K_{i}^{w / H C} \cdot x_{i}^{\text {water }} \\
& x_{i}^{\text {gas }}=K_{i}^{H C / \text { gas }} \cdot x_{i}^{H C}
\end{aligned}
$$

$\alpha_{\text {water }}, \alpha_{H C}$ and $\alpha_{\text {gas }}$ are solved to satisfy:

$$
\sum_{i} x_{i}^{\text {water }}=1, \quad \sum_{i} x_{i}^{H C}=1, \sum_{i} x_{i}^{\text {gas }}=1
$$

The first line (between the reactor and the gas-liquid separator) is modeled, taking into account that a reaction is going on in this part due to the gas entrained through the loop. Corresponding material and heat balances are given here below.

Liquid material balance in the line:

$$
\begin{aligned}
\varepsilon_{l} \cdot \frac{\partial C_{i}^{l}}{\partial t}= & -\frac{\partial\left(v_{s l} \cdot C_{i}^{l}\right)}{\partial z}+k_{L} \cdot a \cdot\left(1-\varepsilon_{g}\right) \cdot\left(\frac{P_{i}}{H_{i}}-C_{i}^{l}\right) \\
& +\sum_{j} \mu_{i j} \cdot r_{j} \cdot \rho_{s} \cdot \varepsilon_{s}
\end{aligned}
$$

Gas material balance in the line:

$$
\frac{\partial\left(\frac{\varepsilon_{g}}{v_{s g}} \cdot F_{i}^{g}\right)}{\partial t}=-\frac{\partial F_{i}^{g}}{\partial z}-k_{L} \cdot a \cdot S_{r}^{e q} \cdot\left(1-\varepsilon_{g}\right) \cdot\left(\frac{P_{i}}{H_{i}}-C_{i}^{l}\right)
$$

Heat balance in the line:

$$
\begin{aligned}
& \rho_{\text {slurry }} \cdot C_{p_{\text {slury }}} \cdot\left(1-\varepsilon_{g}\right) \cdot \frac{\partial T}{\partial t}=-\rho_{\text {slurry }} \cdot C_{p_{\text {slurry }}} \\
& \cdot\left(v_{s l}+v_{s s}\right) \cdot \frac{\partial T}{\partial z}+\sum_{j} \varepsilon_{s} \cdot \rho_{s} \cdot r_{j} \cdot\left(-\Delta H_{j}\right)
\end{aligned}
$$

The gas-liquid separator is solved as a small bubble column reactor including the same material and thermal balances as for the main slurry bubble column reactor.

\subsection{Cooling System Modeling}

The tubular heat exchanger was designed according to a thermal stability study in order to avoid multi-steady states, which are the source of instabilities. A heat exchange area is targeted and a geometrical calculation is done using a square or a triangular arrangement, a tube diameter and a pitch (estimated by calculation on an infinite medium). Due to reactor wall constraints the real heat exchange area is then reevaluated. Once the heat exchanger design is fixed, the boiling feed

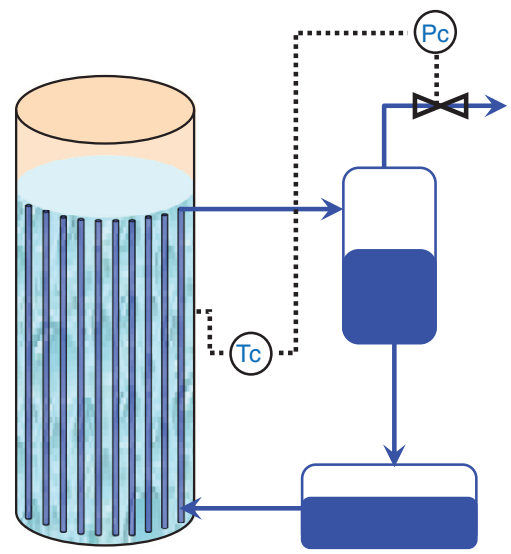

Figure 14

Cooling system.

water circuit is described in order to simulate the heat transfer through the tubes (Fig. 14). Steam pressure is controlled in order to tune the cooling temperature in the tubes.

\subsection{Numerical Aspects and Parameter Estimation}

The model was solved using a discretization scheme based on finite differences. For second- order derivative terms a centered discrete scheme was used, and for first- order derivative terms an upwind scheme was used. For time integration, the Lsode solver was used.

The kinetic parameters are optimized (Tab. 3) using a Levenberg Marquardt algorithm. A set of experimental data collected in a small stirred tank reactor $(1 \mathrm{~L})$, for various operating conditions, was used for optimization. The initial active site concentration was determined according to the amount of cobalt impregnated on the alumina. In this work, it was considered that one atom of cobalt metal constitutes one active site. Data collected in the pilot unit of SNZ were used for model validation.

\subsection{Model Validation}

Two versions of the model were compared with experimental data from the pilot unit of SNZ with a former catalyst. Version V1.0 corresponds to the model including the global CO conversion kinetic model. Version 2.0 corresponds to the model including the micro-kinetic model. Table 4 shows a comparison between both models and data from the industrial unit (column SNZ). This comparison was made using the kinetic parameter determined on the lab-scale tool (stirred tank reactor of $1 \mathrm{~L}$ ). Therefore, the model was validated with independent data from the SNZ unit. 
TABLE 4

Comparison between pilot plant data and both versions of the reactor model

\begin{tabular}{c|c|c|c|c}
\hline & & $\begin{array}{c}\text { SNZ } \\
\text { experimental } \\
\text { data }\end{array}$ & $\begin{array}{c}\text { Simulator } \\
\text { V1.0 }\end{array}$ & $\begin{array}{c}\text { Simulator } \\
\text { V2.0 }\end{array}$ \\
\hline $\begin{array}{c}\text { Per pass } \\
\text { conversion }\end{array}$ & $\%$ & 44.8 & 44.5 & 45.1 \\
\hline $\begin{array}{c}\text { Cooling system } \\
\text { temperature }\end{array}$ & ${ }^{\circ} \mathrm{C}$ & 212.6 & 211.9 & 212.1 \\
\hline $\begin{array}{c}\text { Degasing drum } \\
\text { temperature }\end{array}$ & ${ }^{\circ} \mathrm{C}$ & 223.3 & 223.2 & 222.9 \\
\hline Alpha paraffin & - & $\alpha_{p}$ & $/$ & $\alpha_{p}$ \\
\hline Alpha olefin & - & $\alpha_{o}$ & $/$ & $1.24 \alpha_{o}$ \\
\hline Alpha alcohol & - & $\alpha_{a}$ & $/$ & $/$ \\
\hline CH ${ }_{4}$ selectivity & $\mathrm{mol} \%$ & 47.6 & $/$ & 46.7 \\
\hline $\begin{array}{c}\text { Olefin } \\
\text { selectivity }\end{array}$ & $\mathrm{wt} \%$ & 19 & $/$ & 18 \\
\hline $\begin{array}{c}\text { Alcohol } \\
\text { selectivity }\end{array}$ & $\mathrm{wt} \%$ & 5 & $/$ & $/$ \\
\hline
\end{tabular}

Good agreement is obtained for both developed models. Version 2.0 is also able to predict selectivities in terms of paraffin and olefin distributions (chain length growth parameters: alpha paraffin, alpha olefin). Predicted selectivities are very close to the experimental one. Figure 15 shows a comparison of alcohols composition in water between the model and experimental data. Good agreement is also obtained.

The model is able to give catalyst coverage at different locations in the reactor and in the slurry loop. Figure 16 shows the distribution of adsorbed species on the catalyst at the reactor outlet. The unit operates at low $\mathrm{CO}$ conversion ( $45 \%$ per pass) with an inlet syngas diluted with nitrogen ( $20 \%$ vol. dilution). The recycle ratio of gas is 1:1 (in volume) compared with the fresh gas. According to these operating conditions, $\mathrm{CO}$ and $\mathrm{H}_{2}$ partial pressures are very low, which lead to low dissolved concentrations in the liquid phase. Therefore, adsorption of $\mathrm{CO}$ and $\mathrm{H}_{2}$ is not very strong and leads to a low coverage on the catalyst surface and a high amount of free active sites.

When the model is used to predict chain length growth parameters for paraffins and olefins, methane selectivity and the olefin selectivity ratio as a function of the $\mathrm{H}_{2} / \mathrm{CO}$ ratio, the trends are in accordance with the literature (Visconti et al., 2011), showing a decrease in chain length growth parameters and olefin selectivity with the $\mathrm{H}_{2} / \mathrm{CO}$ ratio, and a methane selectivity increase with $\mathrm{H}_{2} / \mathrm{CO}$.

The simulator has been used up to now for scale-up purposes and includes data from new catalysts developed by IFPEN, ENI and Axens.
Water analysis

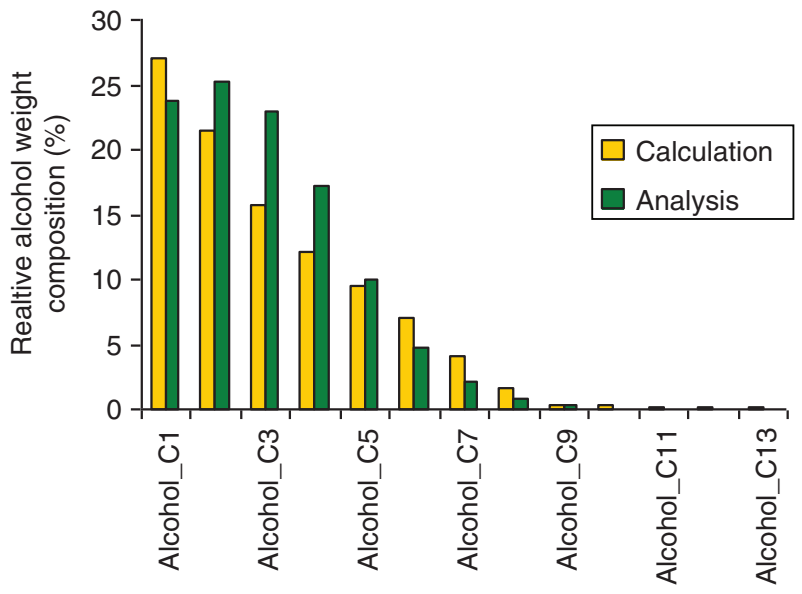

Figure 15

Alcohols composition in water: prediction versus experiments.

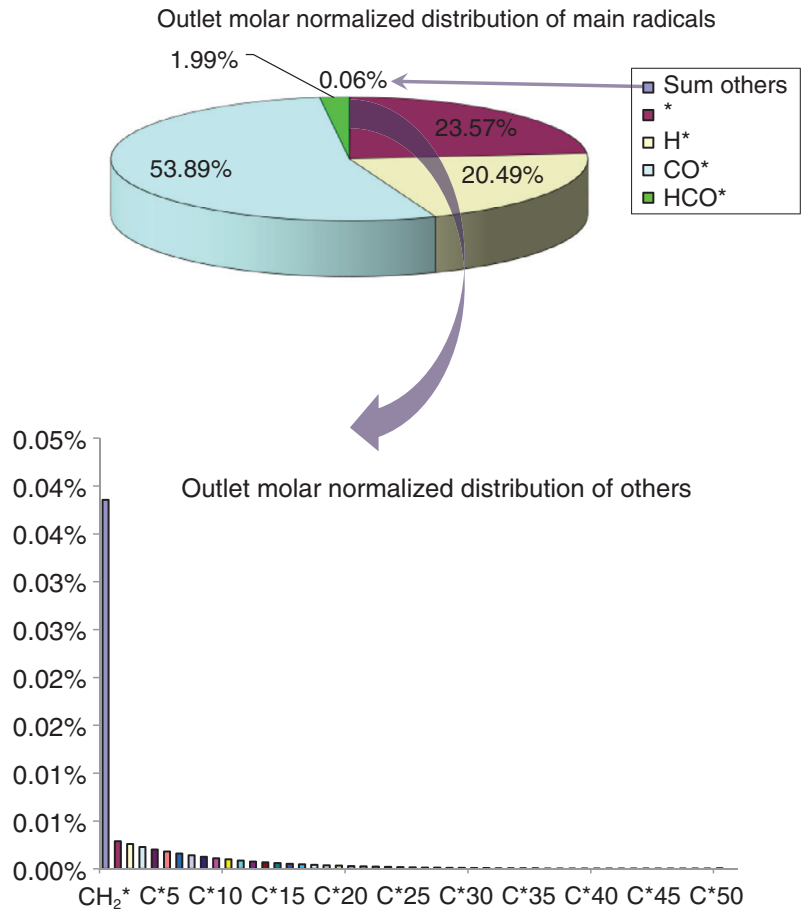

Figure 16

Adsorbed species repartition on active sites at the reactor outlet.

\section{PROCESS GUIDE}

At the end of process development, a technology handbook including all process design rules is provided to license the 
process and establish the process book for every commercialized unit. This handbook will mainly contain:

- the feed specification at the inlet of the reactor: $\mathrm{H}_{2} / \mathrm{CO}$ ratio, inert content and contaminant specifications;

- the FT product properties, characteristics and composition: tail gas and recycle gas, condensates and wax;

- all analysis methods for monitoring and guaranteed product specification;

- for each physical property the handbook will contain the correlation (density, viscosity, etc.) and the associated standard analysis method;

- the catalyst physical and chemical properties;

- pilot performance results and scale-up prediction strategy (catalyst management)

- the normal start of run and end of run operating conditions and procedures;

- the material recommendations for each section;

- the chemical products;

- the instrumentation recommendations for the reactor and the slurry specific equipment;

- the kinetic data acquired on the catalyst during the development step;

- a reactor model which contains the thermodynamic model, the hydrodynamic model, and kinetic and heat and mass transfer knowledge to perform the design;

- design rules for main equipment: reactors, and $\mathrm{G} / \mathrm{L}$ and L/S separation systems;

- control loop strategy for the critical equipment.

The FT technology handbook is the final document from the process development strategy approach presented in Figure 5.

\section{CONCLUSIONS}

This paper described the process development strategy implemented for the Fischer-Tropsch process developed by IFPEN/ENI/Axens. After a preliminary process study for the scheme, and reactor and operating conditions, a large amount of work was devoted to the selection and optimization of catalyst performances on one hand, and the scale-up of the reactor by studying the hydrodynamics of a slurry bubble column on different scales on the other hand. Finally, an original approach was implemented to validate both the process and catalyst on an industrial scale. ENI and IFPEN have shown the pertinence of combining a $20 \mathrm{bpd}$ unit in ENI's Sannazzaro refinery, with cold mock-ups equivalent to 20 and 1000 bpd and a special "Large Validation Tool" which reproduces the combined effect of chemical reaction condition stress and mechanical stress equivalent to a 15000 bpd industrial unit. Accompanying this work, dedicated analytical techniques have been developed to accurately demonstrate product specification can be achieved, and a dedicated complex model has been developed to simulate the whole process (reactor and separation train) to predict and optimize process performances on an industrial scale. While these tools have proven to be efficient for developing an industrial-scale FT catalyst, they predict in a representative manner fine formation, activity and selectivity of improved catalysts and/or for optimization of operation conditions to increase the capacity per train.

\section{REFERENCES}

Albal R.S., Shah Y.T., Carr N.L., Bell A.T. (1984) Mass transfer coefficients and solubilities for hydrogen and carbon monoxide under Fischer-Tropsch conditions, Chem. Eng. Sci. 39, 5, 905-907.

Bartholomew C.H. (2001) Mechanisms of catalyst deactivation, Applied Catal. A: General 212, 17, 60.

Bartholomew C.H., Farrauto R.J. (2006) Fundamental of Industrial Catalytic Processes, 2nd edn., Wiley \& Sons.

Bertoncini F., Marion M., Brodusch N., Esnault S. (2009) Élucider la composition moléculaire des produits obtenus par la réaction de Fischer-Tropsch catalysée par le cobalt par chromatographie gazeuse bidimensionnelle : méthodologie et application, Oil \& Gas Science and Technology - Rev. IFP 64, 1, 79-90.

Bukur D.B., Patel S.A., Matheo R. (1987) Hydrodynamic studies in Fischer-Tropsch derived waxes in a bubble column, Chem. Eng. Comm. 60, 63-78.

Charpentier J.C. (1981) Mass-transfer rates in gas-liquid absorbers and reactors, Advances in Chemical Engineering 11, 1-133.

Dry M.E. (2002) The Fischer-Tropsch process: 1950-2000, Catalysis Today 71, 227-241.

Degaleesan S., Dudukovic M.P., Toseland B.A., Bhatt B.L. (1997) A two-compartment convective-diffusion model for slurry bubble column reactors, Ind. Eng. Chem. Res. 36, 4670-4680.

den Breejen J.P., Sietsma J.R.A., Friedrich H., Bitter J.H., de Jong K.P. (2010) Design of supported cobalt catalysts with maximum activity for the Fischer-Tropsch synthesis, J. Catal. 270, 146, 152.

Eggenhuisen T.M., Munnik P., Talsma H., de Jongh P.E., de Jong K.P. (2012) Freeze-drying for controlled nanoparticle distribution in $\mathrm{Co} / \mathrm{SiO}_{2}$ Fischer-Tropsch catalysts, J. Catal. 297, 306, 313.

Enger B.C., Fossan A.-L., Borg O., Rytter E., Holmen A. (2011) Modified alumina as catalyst support for cobalt in the FischerTropsch synthesis, J. Catal. 284, 9, 22.

Fischer N., van Steen E., Claeys M. (2013) Structure sensitivity of the Fischer-Tropsch activity and selectivity on alumina supported cobalt catalysts, J. Catal. 299, 67, 80.

Forbes A. (2009) Economics of GTL, SMI GTL Conference, London, 27-28 Oct.

Forret A., Schweitzer J.-M., Gauthier T., Krishna R., Schweich D. (2003) Influence of scale on the hydrodynamics of bubble column reactors: An experimental study in columns of $0.1,0.4$ and $1 \mathrm{~m}$ diameters, Chem. Eng. Sci. 58, 719-724.

Forret A., Schweitzer J.-M., Gauthier T., Krishna R., Schweich D. (2006) Scale up of slurry bubble reactors, Oil \& Gas Science and Technology - Rev. IFP. 61, 443-458.

Iglesia E. (1997) Design, synthesis, and use of cobalt-based Fischer-Tropsch synthesis catalysts, Applied Catal. 161, 59, 78. 
Krishna R., Ellenberger J. (1996) Gas holdup in bubble column reactors operating in the churn-turbulent regime, AIChE J. 42, 2627-2634.

Krishna R., Urseanu M.I., van Baten J.M., Ellenberger J. (1999) Influence of scale on the hydrodynamics of bubble columns operating in the churn-turbulent regime: experiments $v s$. Eulerian simulations, Chem. Eng. Sci. 54, 4903-4911.

Krishna R., Urseanu M.I., de Swart J.W.A., Ellenberger J. (2000) Gas holdup in bubble columns: operation with concentrated slurries versus high viscosity liquid, The Canadian Journal of Chemical Engineering 78, 442-447.

Miyauchi T., Furusaki S., Morooka S., Ikeda Y. (1981) Transport phenomena and reaction in fluidized catalyst beds, Advances in Chemical Engineering 11, 275-448.

Patel S.A., Daly J.G., Bukur D.B. (1990) Bubble-size distribution in Fischer-Tropsch derived waxes in bubble column, AIChE J. 36, 1, 93-105.

Park S.-J., Bae J.W., Jung G.-I., Ha K.-S., Jun K.-W., Lee Y.-L. (2012) Crucial factors for catalyst aggregation and deactivation on $\mathrm{Co} / \mathrm{Al}_{2} \mathrm{O}_{3}$ in a slurry-phase Fischer-Tropsch synthesis, Applied Catal. A: General 413-414, 310, 321.

Peña D., Griboval-Constant A., Lancelot C., Quijada M., Visez N., Stéphan O., Lecocq V., Diehl F., Khodakov A.Y. (2014) Molecular structure and localization of carbon species in alumina supported cobalt Fischer-Tropsch catalysts in a slurry reactor, Catal. Today 228, 65, 76.

Peña D., Griboval-Constant A., Diehl F., Lecocq V., Khodakov A.Y. (2013) Agglomeration at the Micrometer Length Scale of Cobalt Nanoparticles in Alumina-Supported Fischer-Tropsch Catalysts in a Slurry Reactor, ChemCatChem 5, 728, 731.

Perego C., Bortolo R., Zennaro R. (2009) Gas to liquids technologies for natural gas reserves valorization: The Eni experience, Catal. Today 142, 9, 16.

Potgieter H., van der Westhuizen R., Rohwer E., Malan D. (2013) Hyphenation of supercritical fluid chromatography and twodimensional gas chromatography mass spectrometry for group type separations, Journal of Chromatography A 1294, 0, 137-144.

Rahmim I.I. (2009) Developing Premium Markets for GTL products, SMI GTL Conference, London, 27-28 Oct.

Reuel R.C., Bartholomew C.H. (1984) Effects of support and dispersion on the $\mathrm{CO}$ hydrogenation activity/selectivity properties of cobalt, J. Catal. 85, 78, 88.

Sarup B., Wojciechowski B.W. (1989) Studies of the FischerTropsch synthesis on a Cobalt catalyst II. Kinetics of carbon monoxide conversion to methane and to higher hydrocarbons. Can. J. Chem. Eng. 67, 62-74.
Schantz M.M., Martire D.E. (1987) Determination of hydrocarbonwater partition coefficients from chromatographic data and based on solution thermodynamics and theory, Journal of Chromatography 391, 35-51.

Schulz H., Beck K., Erich E. (1988) Kinetics of Fischer-Tropsch selectivity, Fuel Process Technol. 18, 293-304.

Schweitzer J.M., Viguié J.C. (2009) Oil \& Gas Science and Technology - Rev. IFP 64, 1, 63-77.

Viguié J.-C. (2007) BTL: Advantages and Hurdles, World GTL 7 Summit, April 2007, London.

Visconti C.G., Lietti L., Forzatti P., Zennaro R. (2007) FischerTropsch synthesis on sulphur poisoned $\mathrm{Co} / \mathrm{Al}_{2} \mathrm{O}_{3}$ catalyst, Applied Catal. A: General 330, 49, 56.

Visconti C.G., Tronconi E., Lietti L., Forzatti P., Rossini S., Zennaro R. (2011) Detailed kinetics of the Fischer-Tropsch synthesis on Cobalt catalysts based on $\mathrm{H}$-assisted $\mathrm{CO}$ activation, Top Catal. 54, 786-800.

van der Westhuizen R., Crous R., de Villiers A., Sandra P. (2010) Comprehensive two-dimensional gas chromatography for the analysis of FischerTropsch oil products, Journal of Chromatography A 1217, 52, 8334-8339.

Wendt R., Steiff A., Weinspach P.-M. (1984) Liquid phase dispersion in bubble columns, Ger. Chem. Eng. 7, 267-273.

Wei D., Goodwin J.G., Oukaci R., Singleton A.H. (2001) Attrition resistance of cobalt F-T catalysts for slurry bubble column reactor use, Applied Catal. A: General 210, 137, 150.

Wolters M., van Grotel L.J.W., Eggenhuisen T.M., Sietsma J.R.A., de Jong K.P., de Jongh P.E. (2011) Combining confinement and NO calcination to arrive at highly dispersed supported nickel and cobalt oxide catalysts with a tunable particle size, Catal. Today 163, 27, 32.

Zhang Q., Deng W., Wang Y. (2013) Recent advances in understanding the key catalyst factors for Fischer-Tropsch synthesis, J. Energy Chem. 22, 27, 38.

Cite this article as: C. Boyer, J. Gazarian, V. Lecocq, S. Maury, A. Forret, J.M. Schweitzer and V. Souchon (2016). Development of the Fischer-Tropsch Process: From the Reaction Concept to the Process Book, Oil Gas Sci. Technol 71, 44. 